ISSN: 0514-7336 — ISSN electrónico: 2386-3943

DOI: https://doi.org/10.14201/zephyrus202086191216

\title{
EL APROVECHAMIENTO HISTÓRICO DEL SÍLEX PARA PIEDRAS DE FUSIL. EL CASO DEL RÍO HUERVA (ZARAGOZA)
}

\section{Historical flint exploitation for gunflints. River Huerva case study (Zaragoza)}

Jesús V. Picazo Millán*, Antonio Morgado-Rodríguez**, Javier Fanlo Loras*** y Fernando PÉREZ-LAMBÁN****

* Dpto. de Ciencias de la Antigüedad. Univ. de Zaragoza. C/ Corona de Aragón, 42. 50009 Zaragoza. Correo-e: jpicazo@unizar.es.ID ORCID: https://orcid.org/0000-0002-4726-819X

** Dpto. de Prehistoria y Arqueología. Univ. de Granada. C/ Profesor Clavera, s/n. 18011 Granada. Correo-e: morgado@ugr.es.ID ORCID: https://orcid.org/0000-0002-8227-2194

*** Arqueólogo independiente. Cl Joaquín Costa, 41. 50450 Muel (Zaragoza). Correo-e: javierfanlo@gmail.com. ID ORCID: https://orcid.org/0000-0002-8447-4662

****Arqueólogo de Athmos Sostenibilidad sL. Correo-e: fperezlamban@gmail.com. ID ORCID: https://orcid.org/00000001-9459-6949

Recepción: 22/06/2020; Revisión: 25/07/2020; Aceptación: 31/10/2020

Resumen: A lo largo del s. XVIII y primera mitad del xix el sílex se convirtió en materia prima estratégica para la fabricación de piedras de chispa utilizadas en distintas armas de fuego. El ejército español obtuvo buena parte de sus suministros del Reino de Granada y, a partir de 1760, de las canteras situadas cerca de Zaragoza, en el entorno del río Huerva, comarca que se convirtió en uno de los principales centros de producción como resultado del sistema de contratas establecido por la Corona para el suministro de más de un millón de piedras anuales. En el artículo presentamos las impresionantes huellas arqueológicas de aquellas explotaciones mineras -trincheras, galerías, pozos, escombreras...-, los lugares de transformación y la tecnología de talla empleada, junto con algunos datos documentales de la producción de estos 'pedernaleros', un oficio especializado y gremial, que se extinguió hacia mediados del xIx cuando las armas con llave de chispa quedaron obsoletas. Pero sobre todo queremos dar cuenta de un patrimonio extraordinariamente conservado y prácticamente desconocido que demanda su reconocimiento y puesta en valor.

Palabras clave: sílex; piedras de fusil; minas; canteras; Edad Moderna; Época Contemporánea; valle del Ebro; prospección arqueológica.

AвSTRACT: Throughout the 18th century and the first half of the 19th century, flint became a strategic raw material due to its use in the manufacture of gunflints for different firearms. The Spanish army obtained a large part of its supplies from the Kingdom of Granada -roughly the present day Province of Granada- and, since 1760, from the quarries located near Zaragoza around the Huerva River. This region became one of the main production centers as a result of the contracting system established by the Crown for the supply of more than one million stones per year. In the article we present the impressive archaeological footprints of those exploitations -trenches, galleries, pits, dumps...-, the processing places and the knapping technology used and some documentary data on the production and the specialized craftsmen known as pedernaleros. Pedernaleros 
craft and union trade died out in the mid-19th century when weapons with flintlock mechanism became obsolete. But, above all, we want to give an account for an extraordinarily preserved and practically unknown heritage that demands its recognition and enhancement.

Key words: flint; gunflints; mines; quarries; Modern and Contemporary Ages; Ebro valley; archaeological survey.

\section{Introducción ${ }^{1}$}

La Península Ibérica cuenta con regiones ricas en sílex, circunstancia que fue clave para su explotación por comunidades prehistóricas e históricas. Entre ellas cabe destacar algunos sectores del valle medio del Ebro, con importantes recursos silíceos que fueron aprovechados desde la Prehistoria. Los estudios arqueológicos desarrollados durante el s. xx e inicios del xxi nos ilustran sobre ello (Bardaviu, 1923; Maluquer, 1955; Vallespí, 1959; Álvarez, 1985; Barandiarán y Cava, 1985; Picazo, 1986; Utrilla y Tilo, 1991; Cabello, 2005; Domingo, $2006 . .$.$) , y más recientemente ha habido interesan-$ tes aportaciones relacionadas con la caracterización y distribución del tipo de sílex denominado 'Botorrita' (Leorza, 2013) o 'Monegros' (García y Domingo, 2016; Sánchez et al., 2019) e incluso con la identificación de un nuevo complejo minero neolítico (Picazo et al., 2018; 2019).

Por el contrario, en escasas ocasiones se ha abordado el aprovechamiento de ese sílex en periodos recientes y, cuando se ha hecho, aparece como algo puntual y anecdótico. El panorama comenzó a cambiar a partir del completo estudio de Barandiarán (1974) de un taller de piedras de fusil localizado en los alrededores de Botorrita (Zaragoza) y otros sílex similares de los pueblos vecinos de Mozota y Muel. Este trabajo pionero llegó a la conclusión, entre otras, de que dichos objetos eran el resultado de una

Trabajo realizado con el apoyo de los Proyectos I + D + i HAR2012-36967 Dinámica de la ocupación prehistórica en el valle medio del Ebro durante el Holoceno Superior y HAR2015-65620-P Paisaje y Sociedad: el valle medio del Ebro entre el 6000 y el 500 cal ANE (MINECO/FEDER). Queremos agradecer a los revisores del texto sus enriquecedoras aportaciones y a nuestros colegas R. Domingo y M. Bea las informaciones relacionadas con las explotaciones de La Muela; a L. Fatás los datos inéditos de las excavaciones en el Castillo de los Marqueses de Camarasa de Muel, y a M. ${ }^{\text {a }}$ C. Sopena los dibujos finales de minas, casetas y perfiles geológicos. talla realizada por artesanos itinerantes que producían para un mercado local, vendiendo allí mismo sus productos para las armas de caza (Barandiarán, 1974: 211-212), idea en cierto modo derivada de la modestia del hallazgo frente a los centros productores franceses e ingleses. Sin embargo, recientes prospecciones realizadas en esas mismas localidades y otras del entorno del valle del río Huerva (Pérez-Lambán, Fanlo y Picazo, 2010), así como en el término municipal de La Muela (Bea et al., 2010), han sacado a la luz más evidencias arqueológicas, algunas de las cuales han sido objeto de detallados estudios (Tarrińo et al., 2018). Todo ello comienza a vislumbrar la auténtica dimensión de las explotaciones de sílex de esa comarca.

Trabajos previos han resaltado la calidad del sílex del río Huerva, convirtiendo esta zona, junto al Reino de Granada, en uno de los centros principales para el suministro de piedras de fusil de la Corona española durante los ss. XVIII y XIX, contribuyendo al desarrollo de una auténtica especialización artesanal (Morgado y Roncal, 2009). Esta afirmación quedará plasmada por la amplia documentación arqueológica, hasta ahora inédita, que configura un patrimonio excepcionalmente conservado.

Este artículo presenta una primera síntesis sobre las explotaciones para la producción de piedras de fusil o chispa del río Huerva (Zaragoza) y su entorno a partir de las evidencias arqueológicas registradas en las prospecciones que desde el año 2007 venimos realizando (Pérez-Lambán et al., 2010), a la vez que tratamos de poner nombre a los protagonistas de aquella actividad mediante una aproximación de carácter documental. El conjunto de evidencias arqueológicas generadas por aquellos artesanos del sílex constituye un legado patrimonial único, hasta ahora escasamente conocido. Por ello resulta determinante su investigación para su futura conservación y puesta en valor. 


\section{El sílex y su contexto geológico}

Esta región central del valle del Ebro es, sin duda, una de las más destacadas de la Península Ibérica por la abundancia y calidad del sílex. Este hecho ya fue reconocido por los ingenieros militares a la hora de seleccionar la materia prima más adecuada para la producción de piedras de chispa destinada a los ejércitos reales (De Salas, 1833: 345). Encontramos pruebas documentales y muestras guardadas por el Cuerpo de Artillería en su Academia en el Alcázar de Segovia (Díez, 2005), posteriormente trasladadas al antiguo Museo de Artillería de Madrid (Anónimo, 1856). En el catálogo de ese museo constaban diecinueve objetos de sílex “... de las canteras de Zaragoza”, sin mayores precisiones (Anónimo, 1856: 58-70), que debemos relacionar con la zona del Huerva. De ellos solo se describe el color, indicando que domina el sílex 'acaramelado', con once muestras de distintos tonos -claros, oscuros, opaco manchado de blanco y transparente-; después los sílex negros -3 muestras-, y en menor medida los sílex pardo claro, 'opaco claro' y 'claro manchado'.

Esas variedades de sílex proceden de las formaciones miocenas que afloran en este sector de la depresión media del Ebro. Corresponden a capas de calizas y margas de espesores variables que contienen sílex nodulares de tamaños centimétricos a decimétricos, en ocasiones botroidales. El sílex en posición primaria se incluye dentro de varias unidades geológicas (IGTE, 1998; Pardo et al., 2004):

- Unidad Montes de Castejón -Cenozoico, Neógeno-Mioceno, Aragoniense Medio/Superior-. Está formada en orlas de lagos someros donde aparecen secuencias de calizas y margas de espesores métricos con presencia de sílex nodulares centimétricos sobre todo a techo de la unidad. Los sílex presentan textura micrítica, con frecuente presencia de anillos de Liesegang. Los elementos esqueletales característicos son bioclastos de algas charáceas y ostrácodos. Su ambiente de formación es lacustre.

- Unidad San Caprasio -Cenozoico, Neógeno-Mioceno-. Presenta facies carbonatadas con nódulos de sílex botroidales muy abundantes y de tamaños variables, decimétricos e incluso mayores. Son sedimentos formados en zonas marginales de

Ediciones Universidad de Salamanca / 요요 lagos carbonatados. Esta unidad se sitúa por encima de la anterior e incorpora sílex de grano fino con impurezas de formación lacustre. Se presenta en nódulos o tablas, con intraclastos y ooides que configuran una cierta estructura de laminación paralela, ya sea algal o de granos no esqueletales. Nuevamente de ambiente de formación lacustre.

Ambas unidades se encuentran en la cumbre de plataformas estructurales, conocidas localmente como 'planas', seccionadas por el río Huerva: La Muela en la margen izquierda y las planas de Muel-Jaulín y de María en la margen derecha (Fig. 1). También aparecen nódulos y abundantes clastos en posición secundaria en los glacis que enlazan las plataformas con el fondo del valle.

En la literatura arqueológica este sílex lacustre de grano fino se viene denominando sílex de 'Botorrita' (Mazo y Cuchi, 1992; Leorza, 2013) o 'Monegros' (García y Domingo, 2016; Sánchez et al., 2019).

\section{Las zonas de explotación}

De Salas (1833: 345) señala los reinos de Granada y de Aragón como los centros productores de las mejores "piedras de chispa” y cita las "... canteras de pedernal negro de la Muela; de pedernal rojo en Jaulín y María; de color de castaña en Fuen de todos (sic); y de color de rayo en Valmadrid". Más allá de la vinculación de cada tipo de sílex a municipios concretos, lo cierto es que la extensión documentada de las explotaciones va más allá de los términos citados. Prospecciones sobre el terreno, fotointerpretación y modelos digitales de elevaciones $(\mathrm{MDE})^{2}$ han permitido rastrear unas huellas que

2 MDE generados con resolución de celda de $1 \mathrm{~m}$, mediante la herramienta LAS Dataset to Raster de ArcGIS de ESRI, a partir de datos altimétricos LidAR distribuidos por el Instituto Geográfico Nacional (http://www.ign.es/ign/main/ index.do) con una densidad de 0,5 puntos $/ \mathrm{m}^{2}$. Esta tecnología se está revelando de notable potencial para el estudio de paisajes históricos (Crutchley, 2015) y prehistóricos, con excelentes resultados en zonas mineras, como el complejo de la Edad del Bronce de Mitterberg (Stöllner, 2014: 152), donde se documenta un sistema de explotación basado en zanjas y pozos, similar al que estamos estudiando.

Zephyrus, LXXXVI, julio-diciembre 2020, 191-216 
194 J. V. Picazo Millán, A. Morgado-Rodríguez, J. Fanlo Loras y F. Pérez-Lambán / El aprovechamiento histórico del silex...

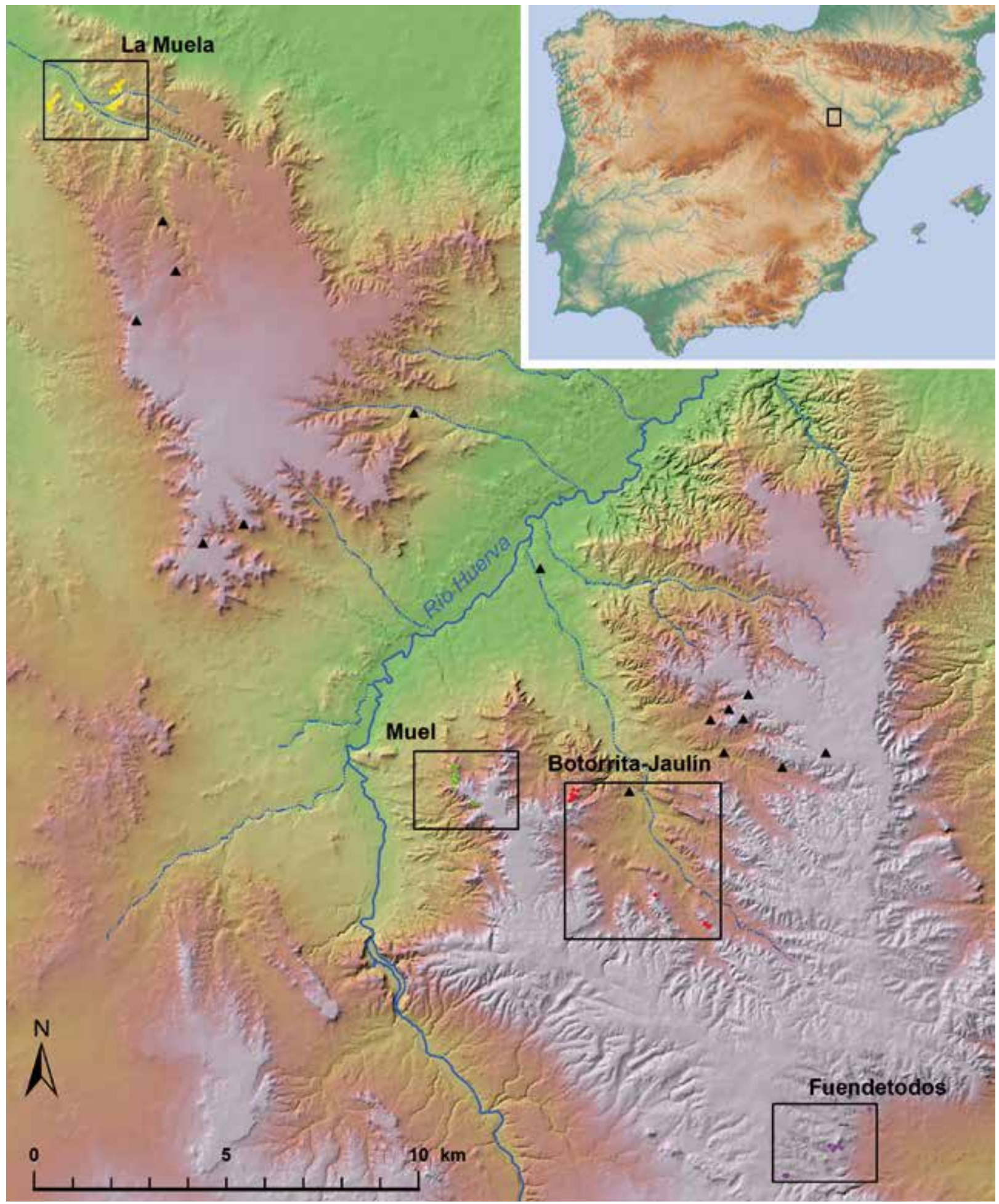

Fig. 1 Valle del río Huerva. Ubicación de las zonas con explotaciones de sílex estudiadas; los triángulos negros señalan indicios registrados por Leorza (2013). 


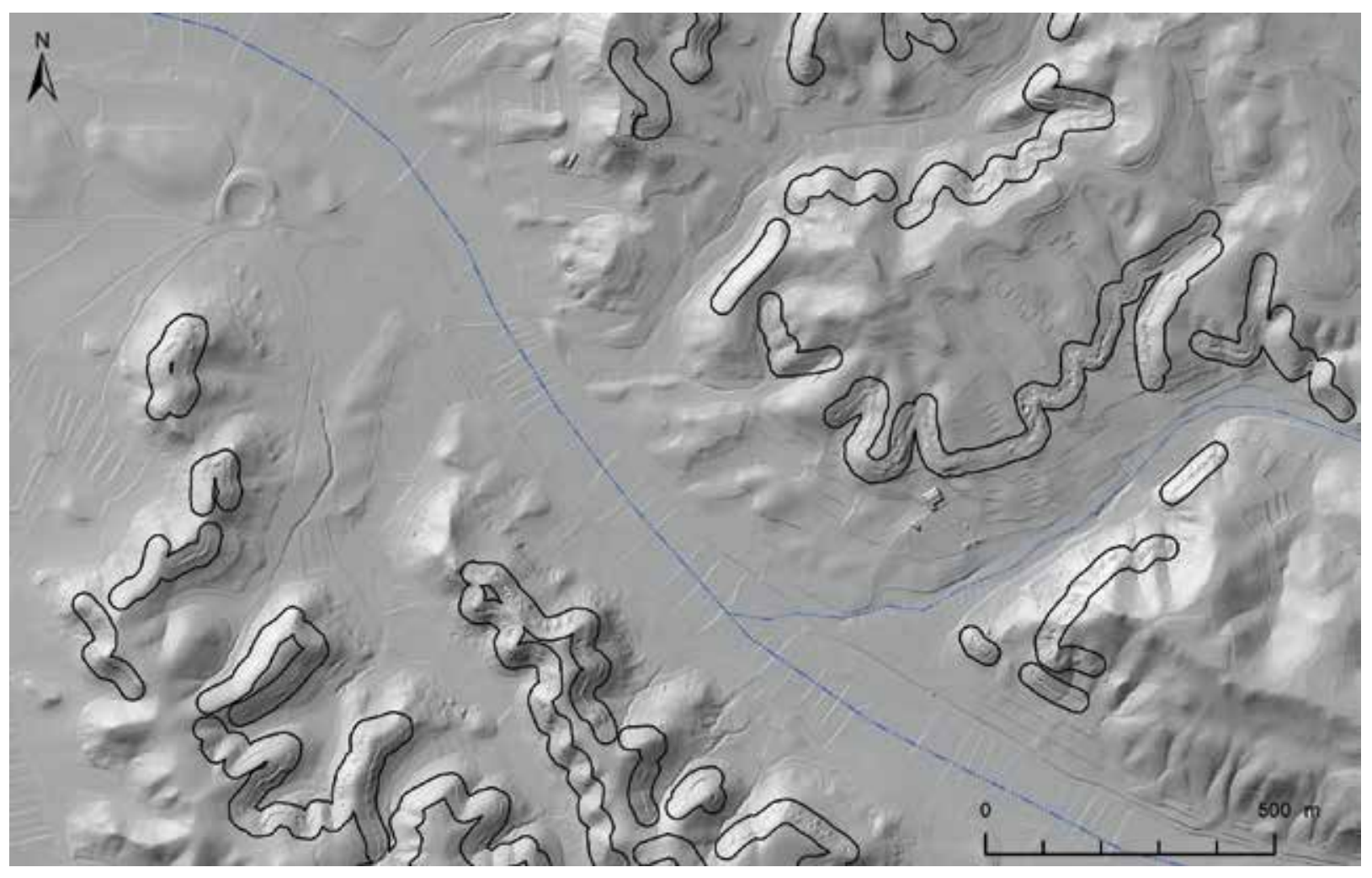

FIG. 2. La Muela, Sector Oeste. MDE con buffer -banda-de $20 \mathrm{~m}$ delimitando las explotaciones.

se extienden también, con diferente intensidad, por los términos de Muel, Botorrita (Pérez-Lambán et al., 2010; Leorza, 2013: 46) y probablemente Torrecilla de Valmadrid, La Puebla de Albortón... hacia el E o Épila y Rueda de Jalón... hacia el o. Toda esta zona conforma un rectángulo de unos 35 x $10 \mathrm{~km}$, centrado en el tramo medio-bajo del río Huerva, dentro del que se inscriben las plataformas estructurales miocenas de La Muela y las 'planas' de María y Muel-Jaulín.

En ese espacio no se ha diseñado una prospección sistemática con objeto de identificar y cartografiar con detalle las explotaciones de sílex, pero sí se han realizado varias actuaciones que permiten constatar la amplitud del fenómeno. Es el caso de las prospecciones acometidas por parte de los firmantes en el tramo central del río Huerva desde el año 2007 (Pérez-Lambán et al., 2010), las realizadas en el término municipal de La Muela en el año 2008
(Bea et al., 2010; Tarrińo et al., 2016) y los trabajos de campo efectuados por Raúl Leorza relacionados con la identificación de las materias primas documentadas en la cabaña mesolítica del Cabezo de la Cruz (Leorza, 2013). A partir de estos trabajos se deduce que las explotaciones son más o menos continuas y afectan a toda el área comentada, si bien es cierto que una serie de zonas parecen constituir los principales focos de explotación, habida cuenta de la densidad de restos y de la notable transformación paisajística que generaron.

\subsection{La Muela, Sector O}

En torno a las partidas de La Ambrolla, Bco. de Almazarro, La Leandra y Opiñén, se desarrollan explotaciones masivas, seguramente las más importantes de la comarca (Fig. 2). Se observan sílex en 
nódulos arrińonados de colores variables, algunos grises muy oscuros, incluso negros, pero predominan los que viran hacia melados.

Los estudios petrográficos realizados por $\mathrm{R}$. Leorza (Picazo et al., 2018: 108), coincidentes con otros publicados (Tarrińo et al., 2016: 235), indican que estamos ante sílex bioclásticos vinculados a ambientes de formación lacustre-palustre. Destacan por un grano muy fino $-<10 \mu-$, micro- o criptocuarzo y, en algunas variedades, el córtex aparece de forma parcial o directamente carecen del mismo. Pueden presentar anillos de Liesegang, así como gran concentración de materia orgánica e impurezas carbonatadas.

Para su extracción se practicaron trincheras, pozos que profundizan hasta alcanzar los estratos de interés y galerías horizontales de poco más de $1 \mathrm{~m}$ de altura, que avanzan en paralelo hasta más de 10 $\mathrm{m}$, llegando a fusionarse lateralmente entre ellas. Pueden reconocerse tramos sinuosos de trincheras prácticamente continuos, ajustados a las curvas de nivel, con recorridos que superan el kilómetro de longitud, siguiendo vetas situadas a diferentes cotas. Las principales coinciden con las curvas de 470 y $480 \mathrm{msnm}$, con recorridos paralelos en algunos sectores.

\subsection{Muel, Sectores E y SE}

El foco principal se encuentra en el entorno de San Borombón, relieve residual de la plana Muel-Jaulín proyectado hacia el N (Fig. 3). Es una zona que se ha explotado de forma muy intensa. Se obtienen sílex de color gris y gris marronáceo, pero también los hay amarillos y rosáceos de mala calidad.

Se reconocen zonas de explotación mediante trincheras más o menos continuas de más de $500 \mathrm{~m}$ de longitud a partir de las cuales se excavan galerías

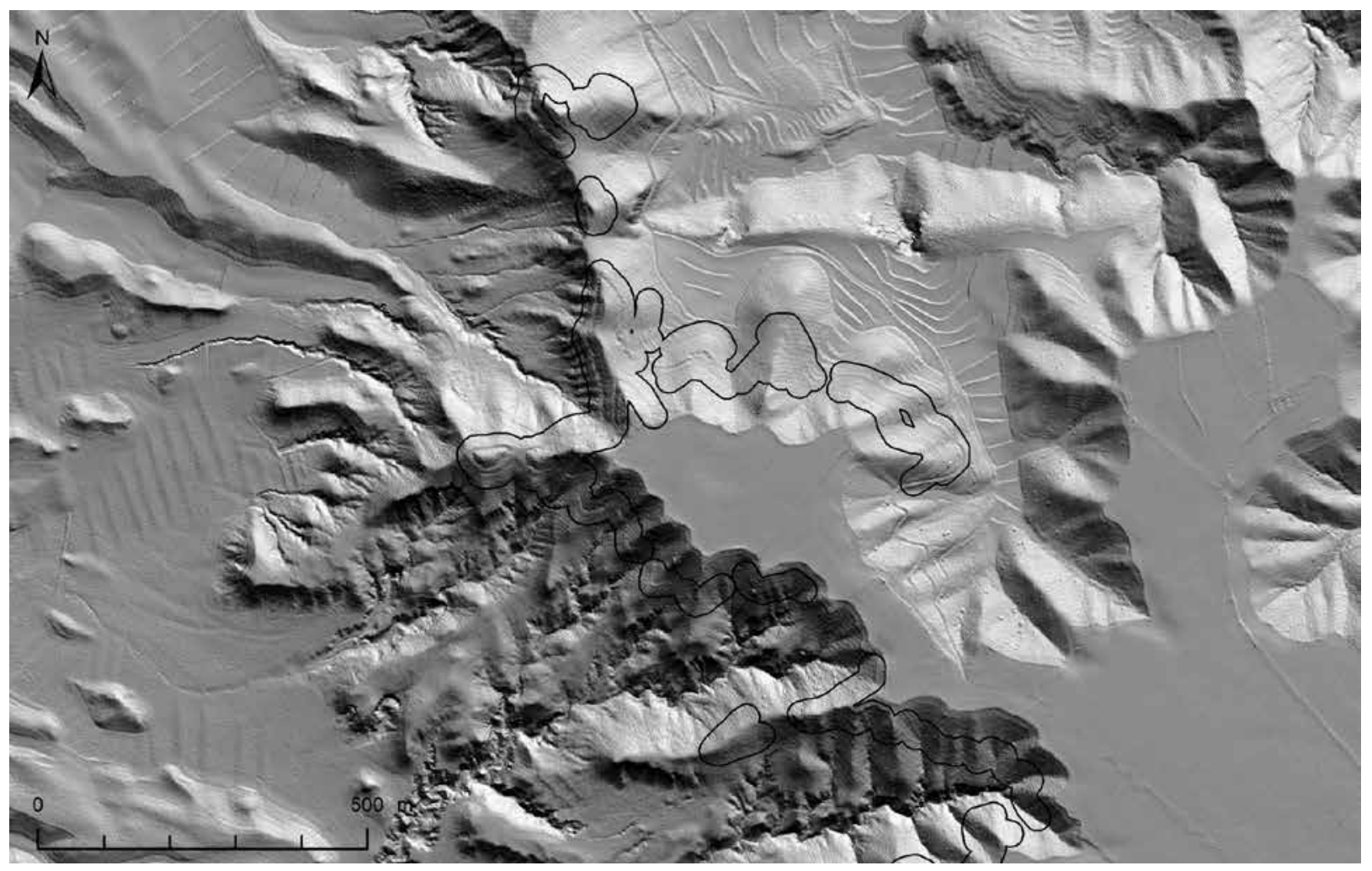

FIG. 3. Zona de San Borombón (Muel). MDE con buffer -banda- de $20 \mathrm{~m}$ delimitando las explotaciones. 

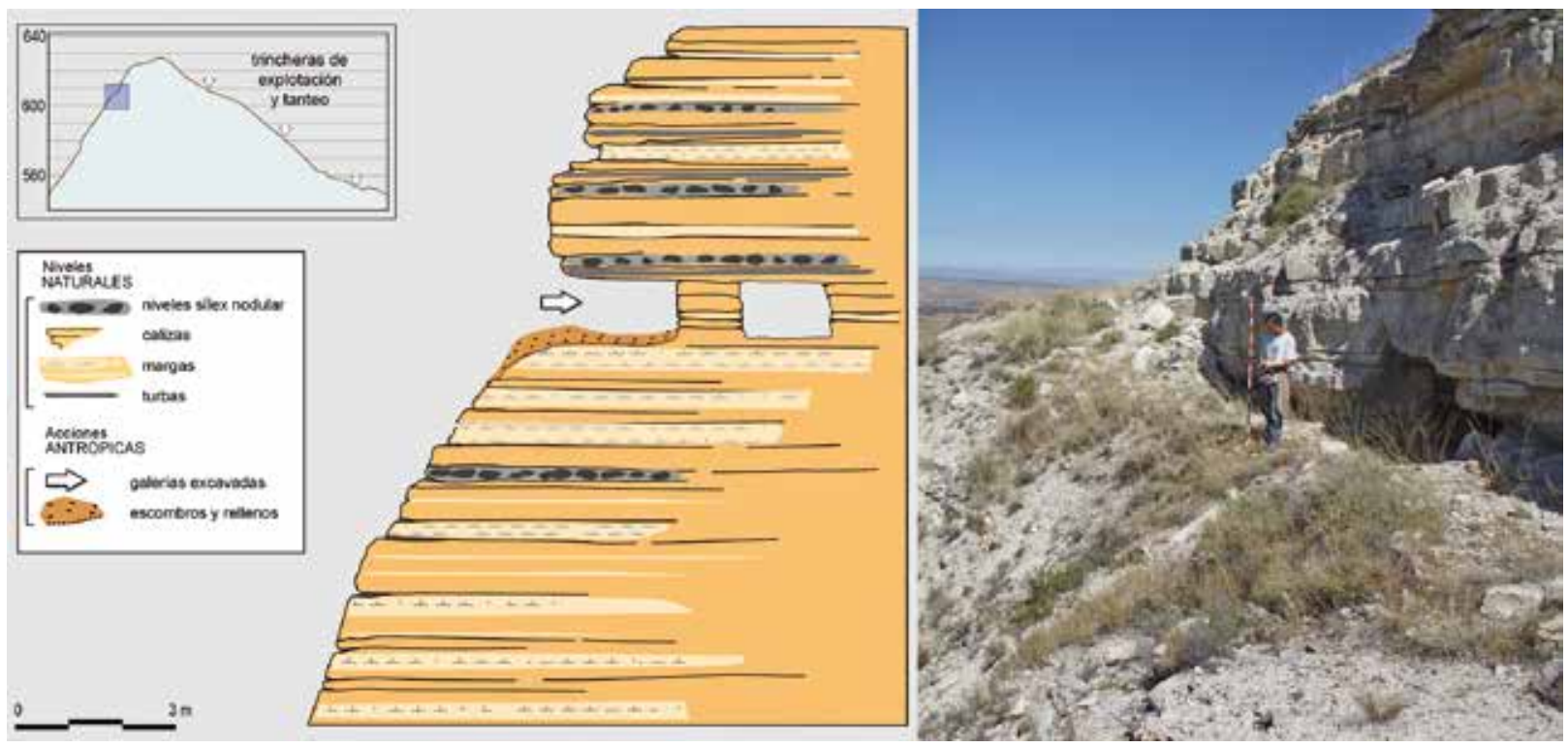

Fig. 4. Perfil estratigráfico de San Borombón con indicación de una de las galerías; a la derecha frente de explotación con las bocas de mina al pie del mismo.

horizontales de cierta amplitud. Las dos principales vetas/trincheras se ajustan a las curvas de $610 \mathrm{y}$ 615 m s.n.m., pero en algunos tramos se identifica una tercera trinchera hacia los $600 \mathrm{~m}$ s.n.m. En el propio cerro de San Borombón (Fig. 4), la base de la trinchera de las explotaciones principales se encuentra a una cota entre los 607 y 608 m s.n.m. con un frente vertical cortando los estratos calcáreos de más de $3 \mathrm{~m}$ de altura. Más al s, en los rebordes de la misma plana, a cota $630 \mathrm{~m}$, se observan trincheras de exploración y tanteo discontinuas, siguiendo un banco de sílex amarillento, masivo, de poca calidad.

\subsection{Alrededores de Jaulin y so de Botorrita}

Es una zona con explotaciones más dispersas, desarrolladas en las estribaciones Este y Norte de la plana de Jaulín y en las lomas alargadas que rodean la depresión donde se encuentra la propia localidad.

Se reconocen trincheras con cierta continuidad jalonadas por pozos-galerías. Al menos se identifican dos líneas de exploración paralelas a cota 610 y 615 con sílex de color gris claro y gris-marronáceo. En las lomas existentes al sur de Jaulín se explotan vetas situadas en torno a la cota 590, entre las que aparece algún afloramiento puntual de un llamativo sílex amarillento.

\subsection{Término de Fuendetodos}

Se han identificado varios conjuntos un tanto dispersos en las partidas de Corral del Blao, Valdezapater, Varello de la Calera, etc., que tienen continuidad hacia La Puebla de Albortón, todos ellos en las estribaciones meridionales de la Plana de María (Fig. 5).

Son explotaciones de importancia con notables escombreras de desbastado asociadas a lo que parecen pozos y trincheras discontinuas con galerías desarrolladas en torno a los 700 y 670 m s.n.m., en ocasiones en los mismos sectores. A cota $670 \mathrm{~m}$, el sílex aparece interestratificado en bancos horizontales entre calizas y margocalizas. En Valdezapater II, en algo más de tres metros de espesor se pueden llegar a contar hasta 10 depósitos horizontales de sílex, 7 de ellos continuos (Fig. 6).

El sílex suele presentarse en forma de riñones relativamente grandes, aplanados, que llegan a enlazar 
198 J. V. Picazo Millán, A. Morgado-Rodríguez, J. Fanlo Loras y F. Pérez-Lambán / El aprovechamiento histórico del silex...

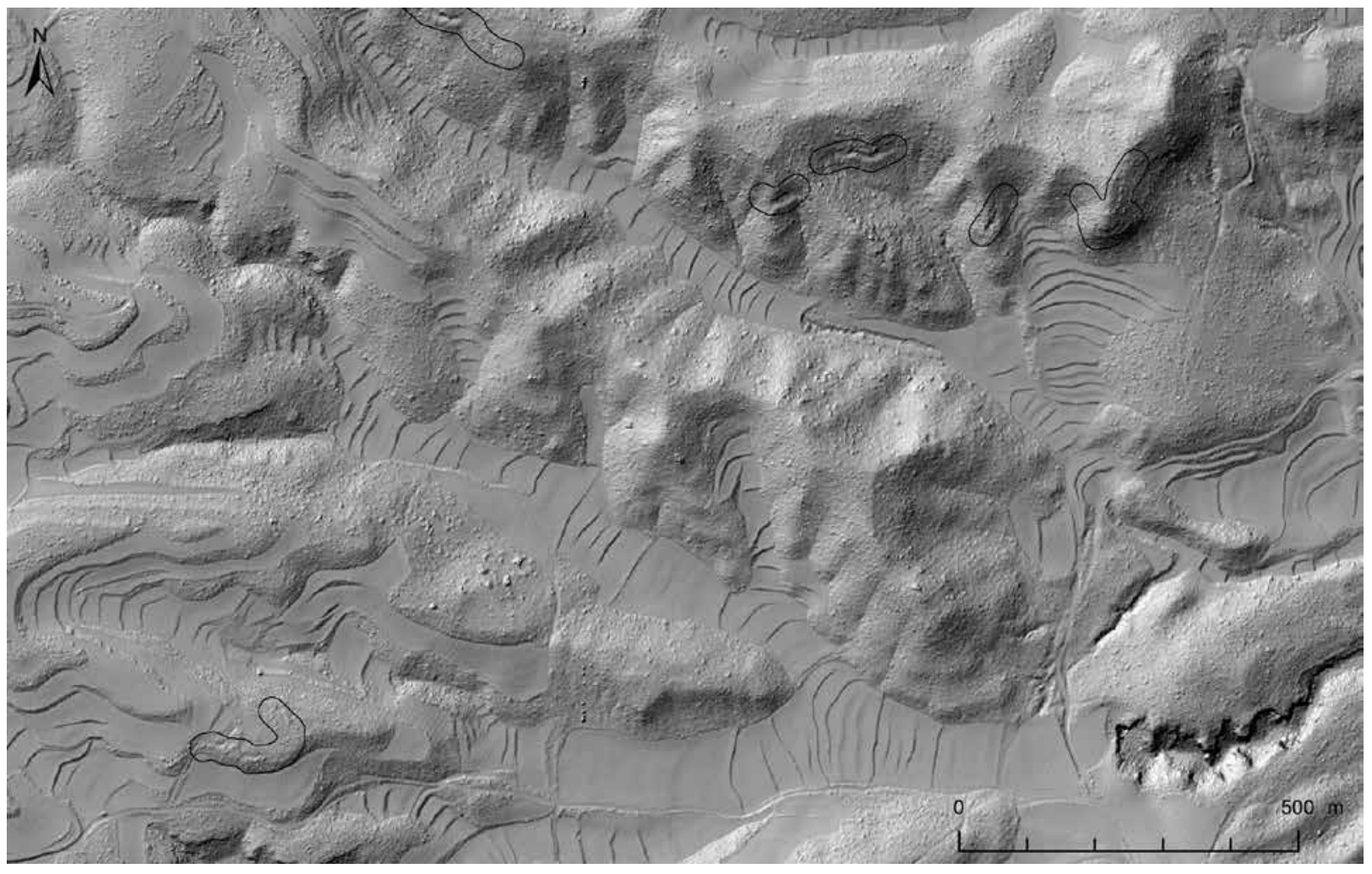

FIG. 5. Zona de Fuendetodos. MDE en el que se observan líneas de puntos y surcos discontinuos en la parte alta de laderas. Buffer -banda-de 20 m delimitando las explotaciones.
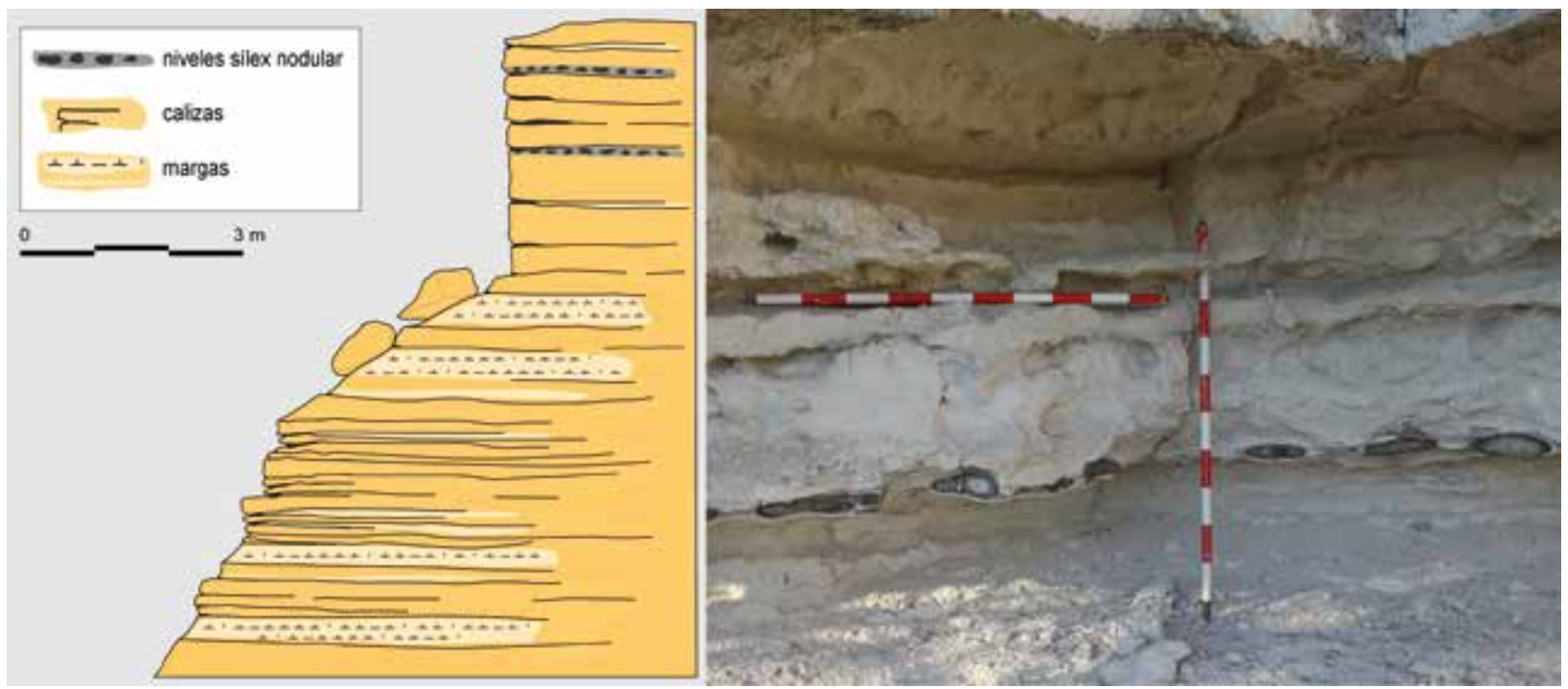

FIG. 6. Valdezapater II (Fuendetodos): perfil estratigráfico y frente de explotación con niveles de silex y negativos de extracciones de nódulos. 
a modo de rosario e incluso formar auténticas tablas. El más buscado se caracteriza por coloraciones grises, más o menos oscuras, y presencia constante de anillos de Liesegang.

\section{Los sistemas de explotación}

\subsection{Minas y canteras}

La forma que adquieren las explotaciones en cada uno de esos sectores se ajusta a un patrón estándar condicionado por las características y disposición de los paquetes calcáreos con niveles silíceos. Por eso mismo, se observan variantes en función de las características concretas de cada zona.

El inicio de las explotaciones se basa esencialmente en la excavación de trincheras longitudinales en las laderas siguiendo los estratos calizos donde se encuentran las principales vetas de sílex. La disposición horizontal de la estratificación miocena favorece que las trincheras se desarrollen a cotas más o menos constantes y que en un mismo sector puedan aparecer dos o tres líneas paralelas a diferentes alturas. Estas trincheras adquieren una sección en $\mathrm{L}$, con un frente más o menos vertical que fácilmente sobrepasa los $2 \mathrm{~m}$ de altura cortando los estratos calcáreos y una base con tendencia horizontal de dimensiones variables en función de la acumulación de escombros. Asimismo, la longitud documentada supera los varios centenares de metros, pero, incluso en el sector de La Muela, se pueden observar explotaciones continuas o casi continuas que superan el kilómetro.

Es relativamente frecuente que esas trincheras se excaven en estrechas lomas que se proyectan desde las plataformas miocenas, como queda patente en la partida de Almazarro de La Muela o San Borombón en Muel. Ello permite atacar los bancos de calizas desde ambos lados, sin tener que excavar galerías demasiado profundas.

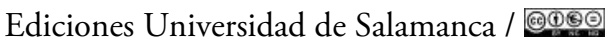

A partir de estas trincheras, cuando se identifican concentraciones de nódulos silíceos se excavan galerías horizontales que profundizan hacia el interior de las plataformas desmontando los bancos

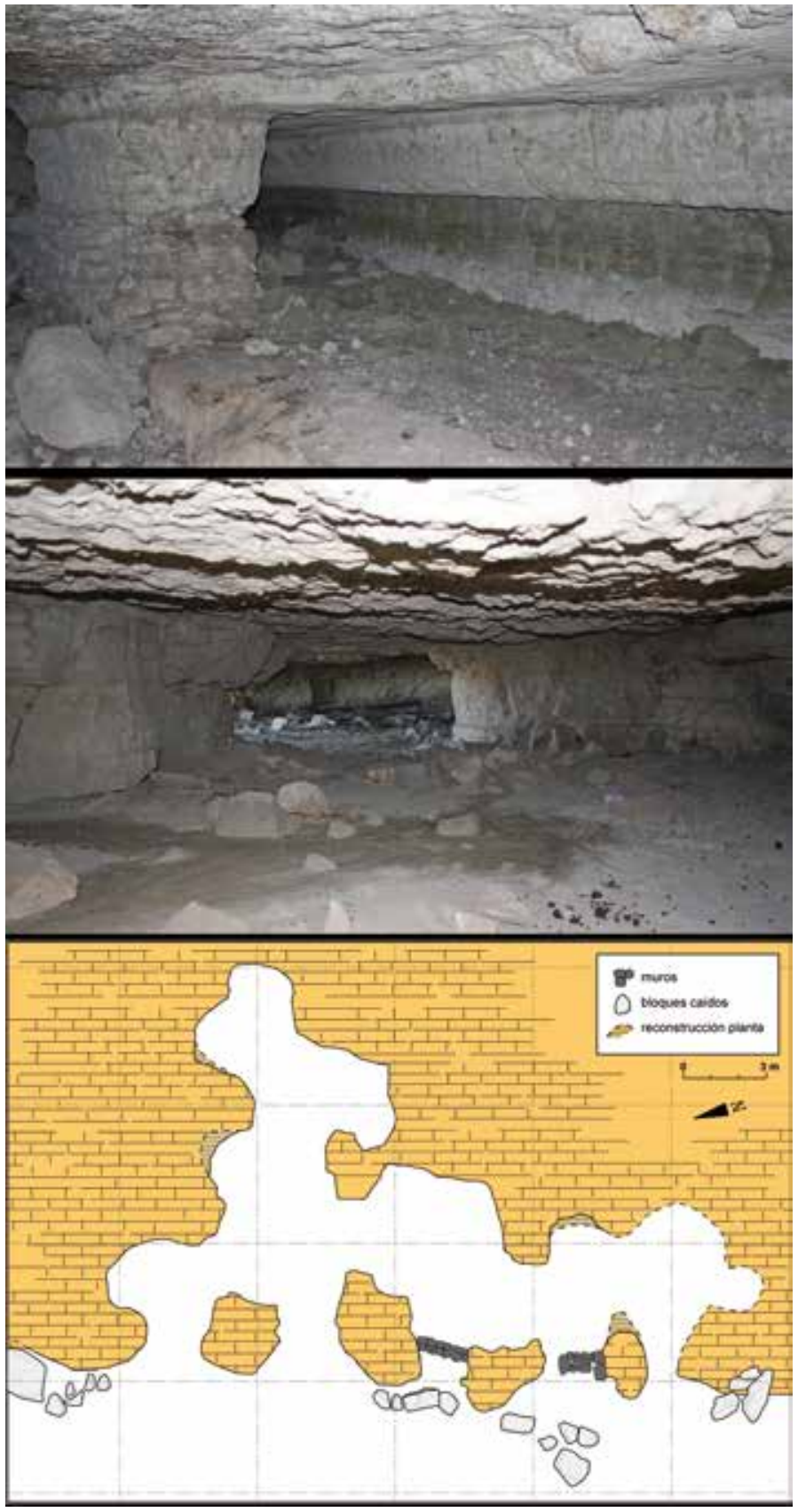

Fig. 7. Arriba minas de Valdezapater I (Fuendetodos), con pilar de sustentación; centro y abajo vista de las galerias de San Borombón (Muel) y planta. 


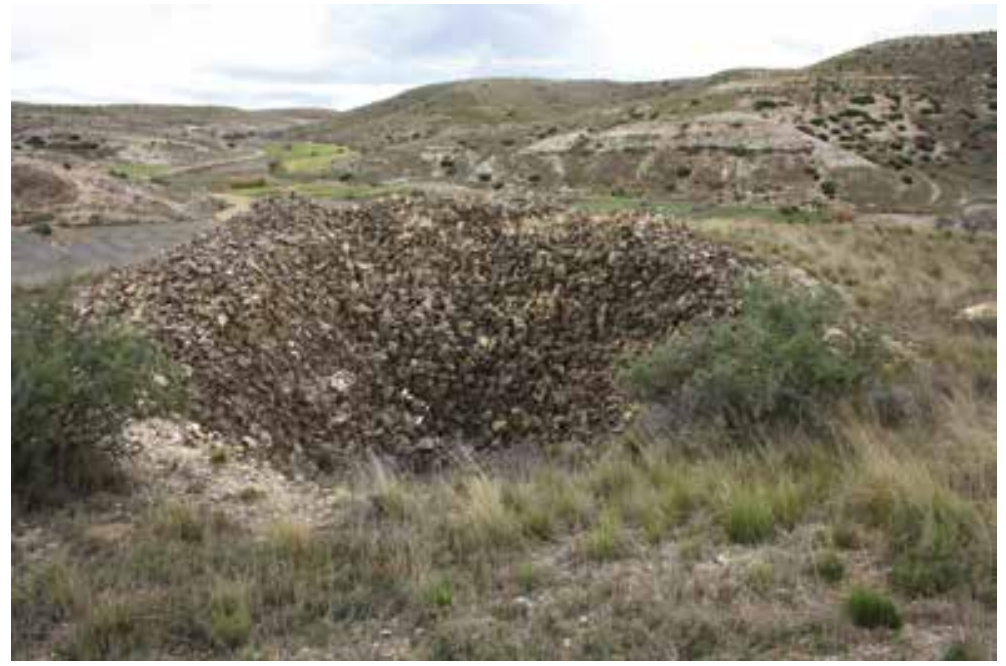

FIG. 8. Pozo y escombrera en La Leandra (La Muela); al fondo serie de escombreras en la parte baja de la ladera a partir de una trinchera de explotación.

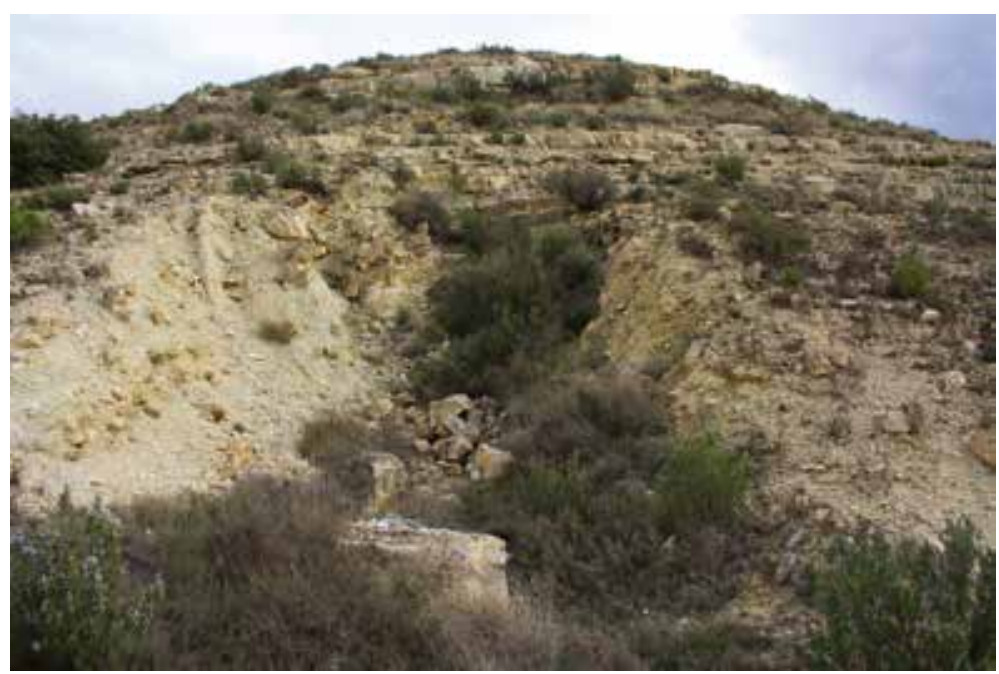

Fig. 9. Opiñén (La Muela): trinchera perpendicular cortando la ladera hasta acceder al banco de calizas.

de calizas y margocalizas (Fig. 7). Están bien documentadas en la zona de Almazarro (La Muela), San Borombón (Muel) y Valdezapater (Fuendetodos), pero se intuyen por el resto del territorio, por lo que pensamos que fue la forma habitual de extraer el sílex. De hecho, las trincheras parecen funcionar como mecanismo de exploración, mientras que las explotaciones en sentido estricto se desarrollan mediante galerías, en cuyo exterior se acumulan

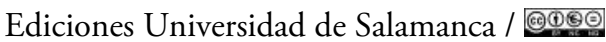

escombreras de entidad que incorporan tanto bloques de caliza como desechos del desbastado de los nódulos e incluso restos de talla de piedras de fusil. Por ello, donde solamente se han llevado a cabo trabajos de exploración y tanteo, no se llegan a encontrar grandes acumulaciones de desechos, ni las trincheras adquieren una entidad relevante.

En lo que hemos podido observar en lugares como Valdezapater, las galerías presentan bocas relativamente estrechas -c. 1-2 m- para ampliarse lateralmente en el interior hasta alcanzar los 5-6 m de anchura, lo que requiere pilares de sustentación, construidos con bloques o tallados en la misma roca, y desarrollos en profundidad que no superan los $10 \mathrm{~m}$ de longitud. La altura es constante, de poco más de $1 \mathrm{~m}$, derivada de la excavación de los paquetes de calizas y/o margocalizas que se disponen en bancos horizontales de esas dimensiones (Fig. 7). En el exterior, junto a la boca, se generan las correspondientes escombreras formando rellanos y conos de derrubios ladera abajo.

En algunas zonas estas galerías se encuentran de forma puntual, jalonando el recorrido de las trincheras, pero, donde hay mayor concentración de sílex, se disponen en batería, pudiendo llegar a fusionarse lateralmente unas con otras. Es lo que parece ocurrir en San Borombón (Muel), donde llegan a configurar una gran sala con aspecto alveolar, consecuencia del avance desigual y fusión de cuatro galerías paralelas con frentes de 3 a $5 \mathrm{~m}$. La profundidad máxima alcanzada es de $15 \mathrm{~m}$ por una anchura cercana a los $20 \mathrm{~m}$ (Fig. 7).

Este modelo presenta algunas variantes como son los pozos (Fig. 8), más o menos alineados siguiendo los límites de los paquetes calcáreos, y las 
trincheras cortas perpendiculares a los mismos (Fig. 9). Ambos procedimientos se utilizan en lugares donde afloran las calizas pero no los niveles silíceos, más profundos y enterrados bajo depósitos de ladera potentes, como sucede en las explotaciones de La Leandra y Opiñén en La Muela, o en el Corral del Blao en Fuendetodos. Los pozos penetran en el subsuelo de forma vertical u oblicua hasta alcanzar los estratos de interés y, suponemos, luego se transforman en galerías horizontales como las descritas anteriormente. Aunque no tenemos constatación fehaciente de ello, es lo que explicaría las imponentes escombreras de roca que se generan junto a los pozos, siendo el modelo de explotación de los principales centros

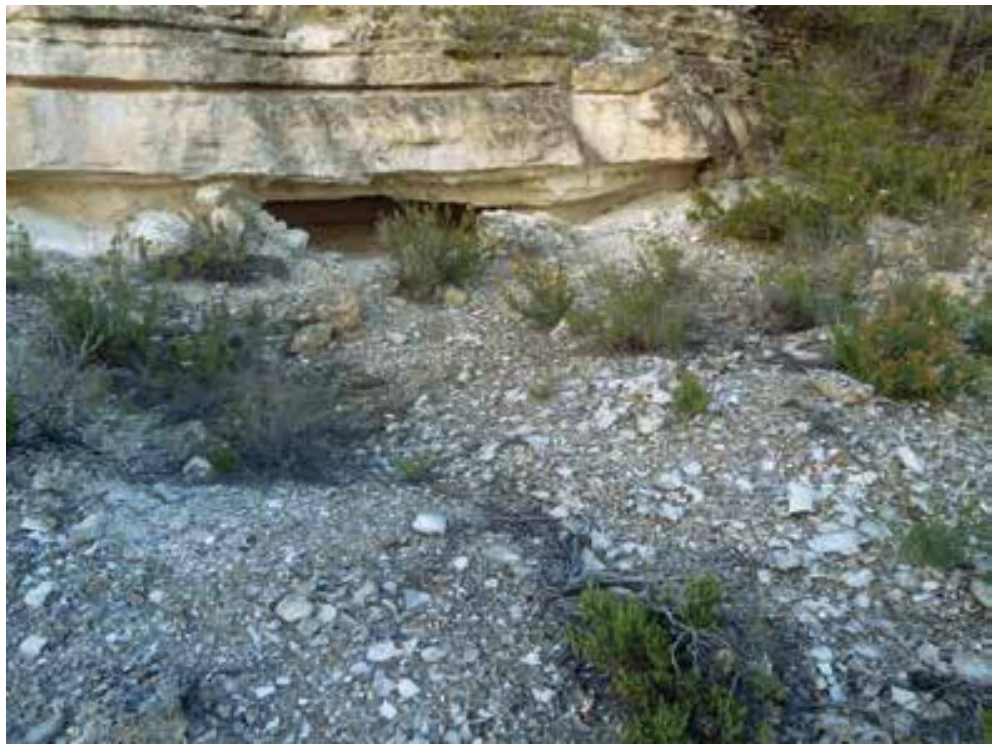

FIG. 10. Varello de la Calera, Fuendetodos: amontonamientos con desechos de talla en la boca de la mina.

\subsection{La transformación del silex}

con pozos de hasta $10 \mathrm{~m}$ de profundidad ligeramente inclinados, asociados a un complejo sistema de galerías que avanzan hasta $9 \mathrm{~m}$ en varias direcciones (Skertchly, 1879: 21-26).

La excavación de trincheras, pozos y galerías supuso la movilización de importantes cantidades de roca que se acumularon junto a las minas o se desparramaron ladera abajo formando conos de derrubios. Dada su magnitud, todas estas acciones tuvieron un impacto significativo en el paisaje que todavía hoy es perceptible en diferente grado. En los alrededores de la localidad de Jaulín, se conservan las huellas de las explotaciones en forma de sutiles líneas horizontales en las partes altas de las laderas, incluso en las orientadas al norte, más regularizadas. Aunque actualmente se encuentran colmatadas y mimetizadas en el paisaje, pueden reconocerse porque generan un leve rellano con vegetación algo más densa, buen indicador en estos contextos semiáridos y cubierta vegetal raquítica. Sin embargo, en zonas como La Muela, se conservan pozos y escombreras sin apenas indicios de regularización. Esta conservación diferencial de los vestigios es un fenómeno a explorar.

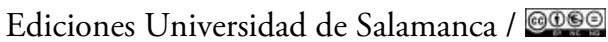

Una vez extraídos los nódulos, el trabajo de decorticado, lascado y, en su caso, fragmentación de los más grandes ${ }^{3}$ se lleva a cabo en el exterior de las galerías, junto a las bocas de las minas o en sus proximidades, aprovechando la 'comodidad' de los rellanos generados por las propias escombreras. De hecho, en algunas explotaciones se acumulan densas concentraciones de desechos formando auténticos conos de derrubios con espesores decimétricos, que se dispersan ladera abajo y que están integrados de forma casi exclusiva por restos de talla (Fig. 10). En esas acumulaciones son frecuentes núcleos discoides, en ocasiones de tamaños notables, dando la sensación de un escaso aprovechamiento de la materia prima o, en su caso, de una selección rigurosa que lleva a desechar aquel material.

3 En el sistema de talla inglés se utiliza el término quartering, que designa la primera fase de manipulación de los nódulos grandes típicos de las canteras de Brandon. Consiste en desgajar fragmentos gruesos de sílex con un martillo pesado de extremos hexagonales, para su talla posterior (Barnes, 1937: 329-330).

\subsubsection{Lugares de procesado}


El trabajo final se realiza en los mismos lugares, e implica tanto la elaboración completa de las piedras de chispa como la obtención de soportes para un acabado posterior en otros lugares. Con cierta regularidad se encuentran piedras terminadas, en proceso de elaboración o rotas en los mismos lugares de desbastado y preparación de los núcleos.

Pero también se aprovechan de forma oportunista otros lugares próximos a los de extracción, como son las pequeńas cavidades que ocasionalmente se abren en los estratos calizos. Hemos podido comprobar esta circunstancia en las covachas del Cabezo Negro de Botorrita o del Varello de la Calera en Fuendetodos, sitios donde se han recuperado algunas piedras terminadas, así como abundantes restos de talla formando amplios conos de desechos dispersos ladera abajo. Sin duda parecen representar refugios ocasionales que permiten seguir realizando estas tareas bajo condiciones meteorológicas poco favorables.

Dentro de este modelo, las explotaciones situadas al oeste del término de La Muela, de nuevo, muestran algunas peculiaridades. Lo más destacado es la limitada presencia de desechos del procesado de los nódulos de sílex en las escombreras que se encuentran junto a las bocas de los pozos de la partida de $\mathrm{La}$ Leandra, lo que apunta al traslado de los nódulos de sílex a una zona especializada de talla. Es el caso de una parcela aproximadamente rectangular de unos $2.000 \mathrm{~m}^{2}$ localizada en la margen derecha de un barranco, sobre una suave ladera orientada al S-SE, bien soleada y protegida del viento dominante del No (Fig. 11). En ella se han identificado más de una decena de amontonamientos de desechos de lascas y esquirlas de más de $1 \mathrm{~m}$ de diámetro, distribuidos en dos líneas a lo largo de unos $80 \mathrm{~m}$ a partir de una cabaña de piedra situada en el extremo oeste, en cuya puerta también se talló (Fig. 19). En alguno de esos amontonamientos se observa una losa plana de caliza que pudo servir de yunque o de asiento para el tallador. Este lugar apunta a una actividad coordinada, ejecutada por cuadrillas de pedernaleros y probablemente realizada en los periodos fríos del año, dada la favorable orientación del lugar.

\subsubsection{La tecnología lítica}

Los restos de la producción de piedras de fusil en el valle del Ebro permiten trazar las líneas maestras de la cadena operativa. En el primer análisis sobre los materiales del Barranco de Botorrita, se propuso un modelo de elaboración que incidía en la ausencia de tecnología laminar y la obtención de lascas mediante la preparación de núcleos de manera

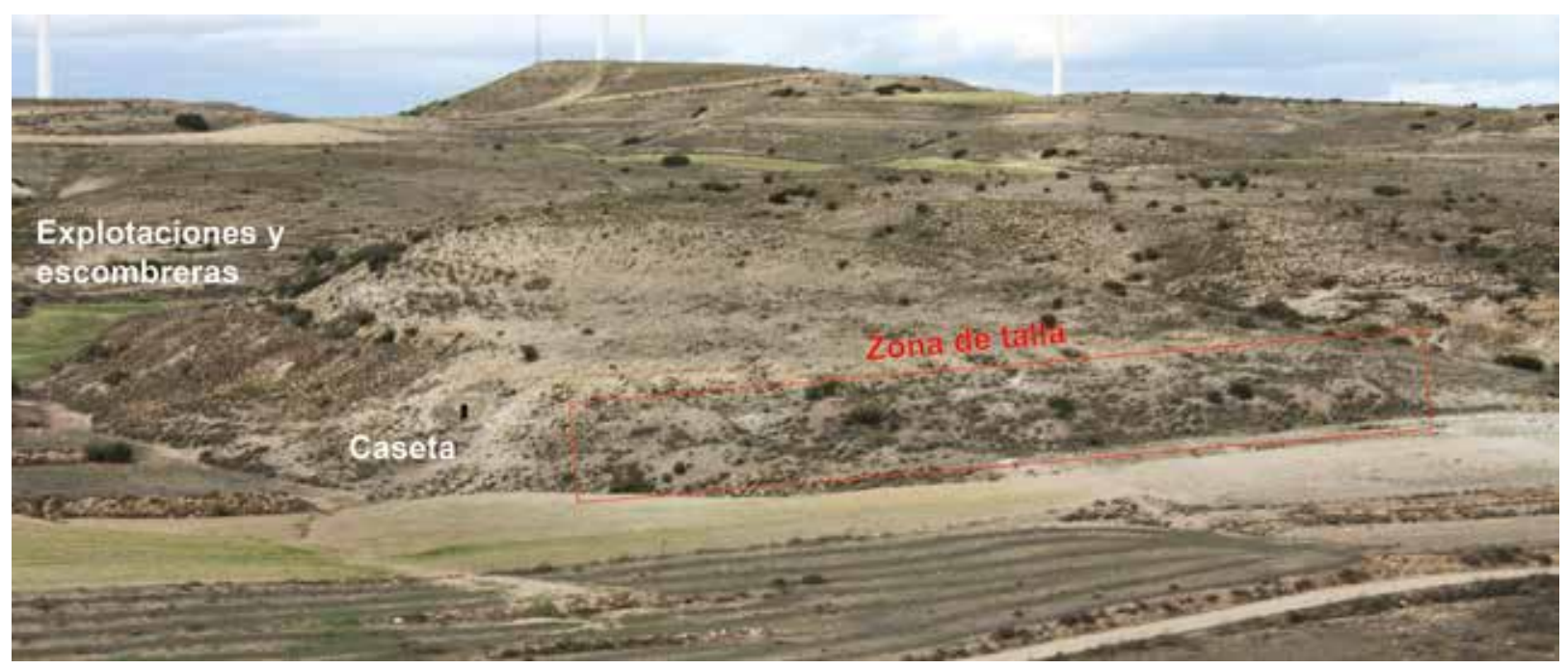

Fig. 11. Zona de talla en la partida de La Leandra (La Muela); son perceptibles los amontonamientos de lascas y esquirlas de silex, donde no arraiga la vegetación. 
asimilable al método levallois (Barandiarán, 1974: 220). La dirección del golpe para el desprendimiento de la lasca, oblicuo, era el rasgo diferencial del método paleolítico (Barandiarán, 1974: fig. 18). La síntesis que presentamos matiza el método de talla propuesto.

\subsubsection{Técnica de talla}

El análisis de las evidencias arqueológicas recogidas en los sitios de transformación indica el uso de objetos de metal. La talla para la preparación y extracción de lascas fue por percusión directa con percutor metálico, como se deduce al observar los estigmas de estos instrumentos en los talones de las lascas, las huellas de percusión fallida y los negativos de bulbos en los núcleos. La mayor parte de los talones son lisos, espesos y presentan, con nitidez, un punto de impacto de unos $5 \mathrm{~mm}$ de diámetro. Este impacto es reconocible por fisuras circulares o subcirculares, a veces múltiples, alrededor del contacto
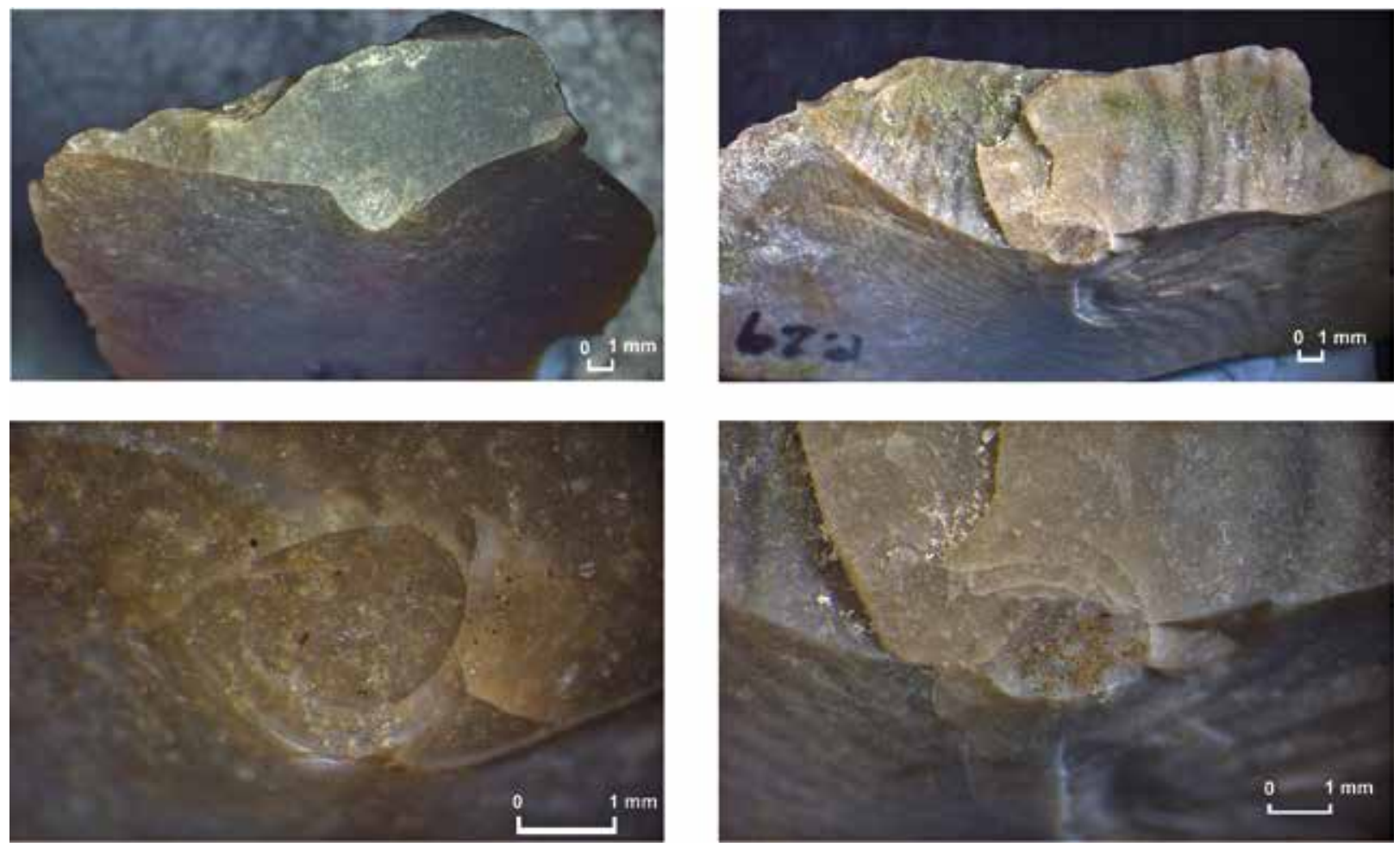

FIG. 12. Estigmas producidos por la utilización de percutor de hierro en lascas: izda.) procedentes de La Ambrolla en La Muela y dcha.) de la Covacha de Cabezo Negro de Botorrita, con signos de oxidación. 


\subsubsection{Métodos de talla}

Se tiende a la producción de las lascas anchas y espesas extraídas de núcleos de diversa tipología mediante varios métodos de talla. En parte, estas variantes estuvieron determinadas por la calidad y tamaño de los nódulos. En algunos afloramientos, el sílex se presenta en grandes nódulos alargados, conteniendo el de mejor calidad justo por debajo del córtex, pues el interior es calcáreo y menos cristalino. Dado que los soportes para piedras de fusil requieren de un sílex de alta calidad, se desarrolló un método de talla alternante, centrípeto y perimetral, aprovechando la mejor silificación y dejando prácticamente sin agotar el nódulo. El resultado ofrece grandes núcleos, a veces, de aspecto bifacial, con frecuentes restos de córtex en el centro; estas piezas pueden ser confundidas con esbozos de bifaces, si solo se tienen en cuenta criterios formales (Figs. 13, n. ${ }^{\text {s }} 3-4$ y 14, n. ${ }^{\text {os }} 1-2$ ). Los nódulos de mejor calidad permiten la plena producción de lascas que genera núcleos discoides de sección bipiramidal o biconvexa (Fig. 14, n. ${ }^{\text {os } 3-6) ~ y ~ r a r a m e n t e ~ a p l a n a-~}$ dos, con disposición alternante de las extracciones de lascas. Por último, los nódulos de sílex de menor tamaño y buena calidad fueron tallados aplicando un método basado en la creación preferente de uno, más raramente dos, planos de percusión lisos, con extracciones unidireccionales cuyos últimos negativos suelen ocupar la totalidad del frente (Fig. 15). Este último método está muy representando en el Reino de Granada (Morgado y Roncal, 2009).

Las mejores lascas obtenidas eran transformadas mediante diferentes modos de retoque, para cuya caracterización seguimos la sistemática de Inizan $e t$ al. (1995: 89). El método dominante se basa en un proceso que comienza con la eliminación del marcado talón mediante retoque directo, cubriente y rasante/semiabrupto. Finalmente se transformaba el resto de filos por retoque directo, invasor/cubriente y rasante hasta obtener bordes rectos y una morfología cuadrangular (Fig. 16, n. ${ }^{\text {os }} 7-9$ y 13-14). El segundo método consistía en fracturar las lascas, a veces de tendencia laminar, para posteriormente realizar un retoque directo, semiabrupto y corto sobre dichas fracturas intentando conservar prácticamente sin retocar los lados restantes (Fig. 16, n. ${ }^{\text {os }}$ 10-12).

\subsubsection{Los productos}

Los manuales del Cuerpo de Artillería clasifican las piedras atendiendo al arma a la que se destinaban,
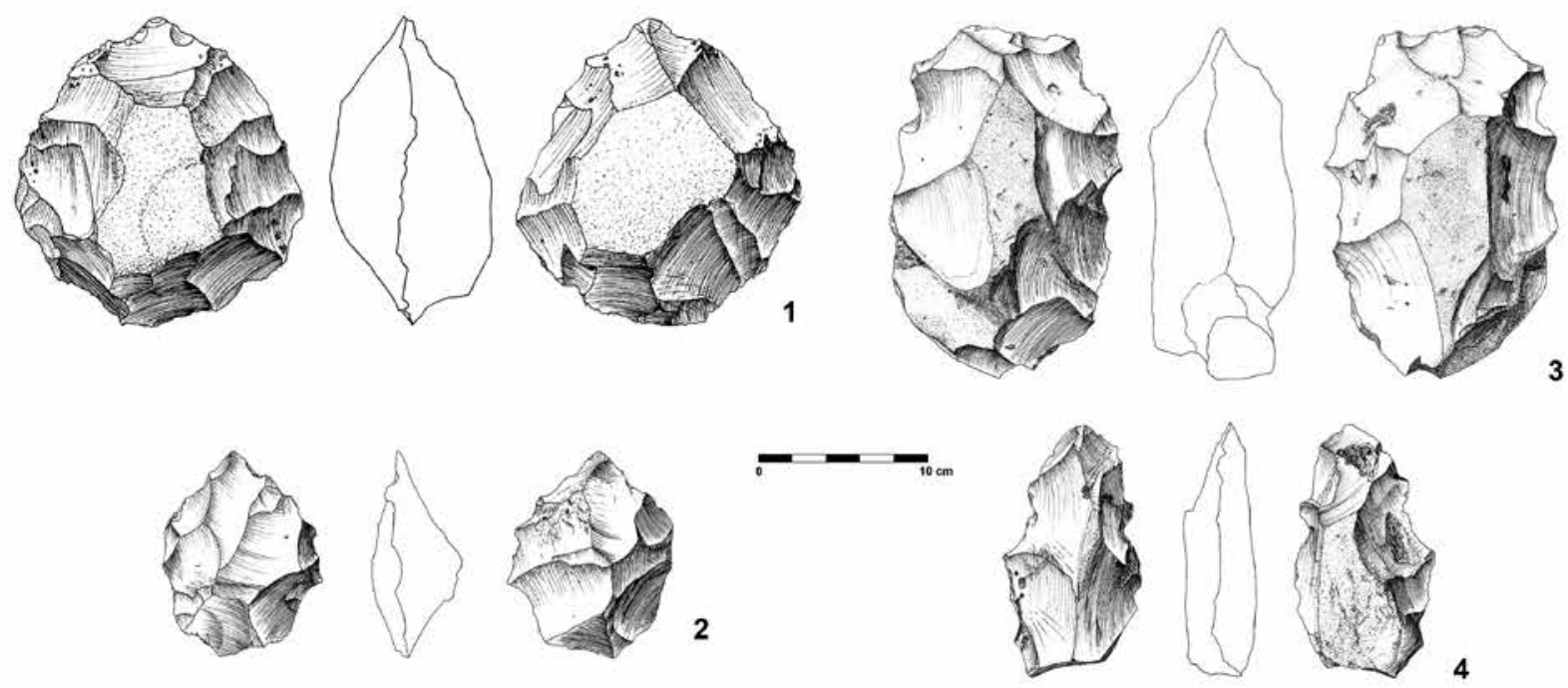

Fig. 13. Paridera de Joserito, Jaulin: 1-2) núcleos discoides de grandes dimensiones y 3-4) con morfología de pseudobifaces. 

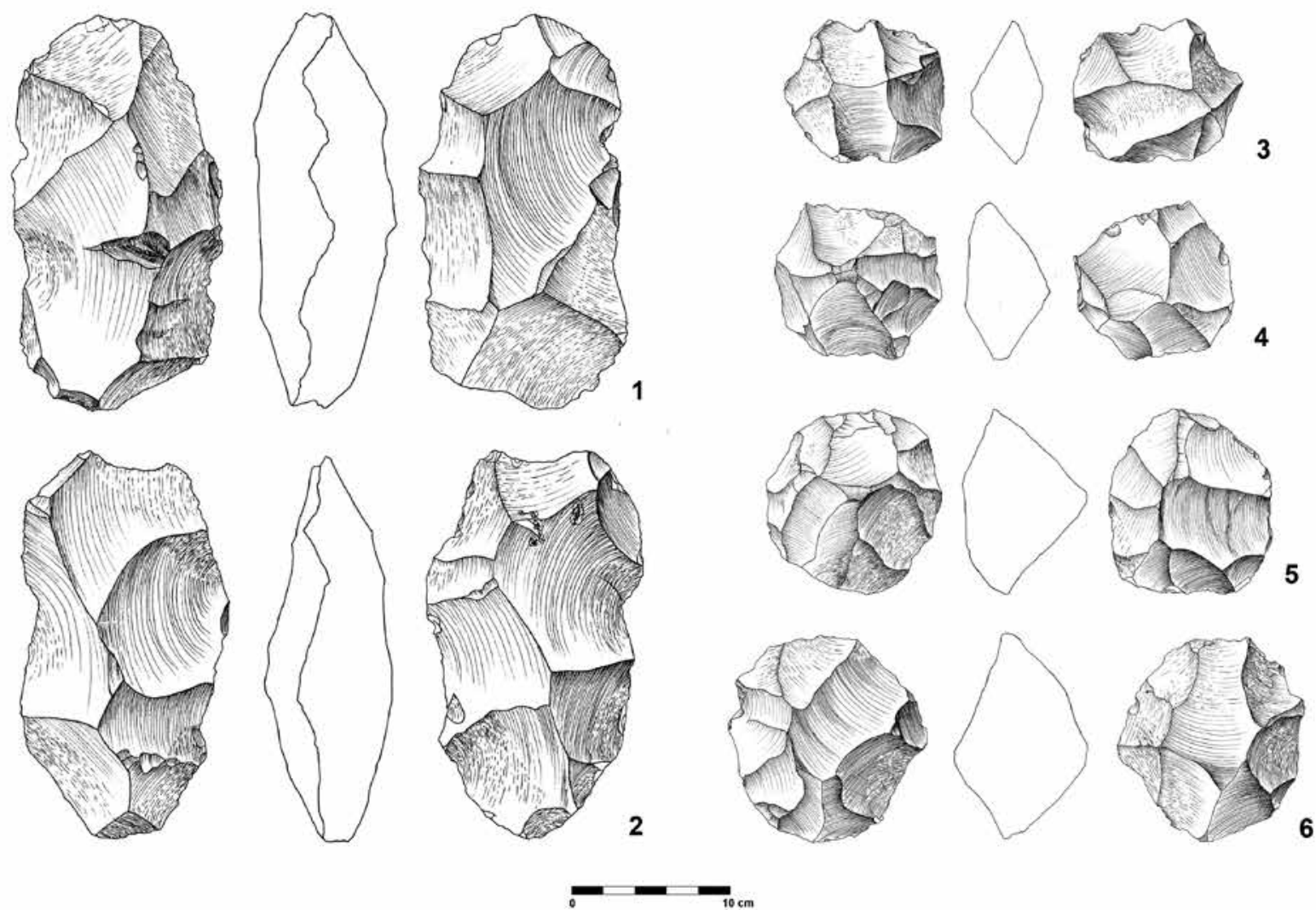

Fig. 14. San Borombón Tramo V, Muel: 1-2) núcleos de grandes dimensiones alargados (pseudobifaces) y 3-6) discoides de sección bipiramidal.

fusil, tercerola o carabina y pistola (Morgado y Roncal, 2009: 102), y sabemos por diferentes documentos que las contratas solían especificar el número de cada tipo, siendo las de fusil las más requeridas (De Salas, 1833: 345).

En la zona del Huerva no hemos realizado una búsqueda sistemática que permita explorar la tipología de las piedras de chispa producidas, pero, como hemos comentado, de vez en cuando se encuentran algunas en las zonas de talla o en los alrededores de las mismas, aunque en la mayor parte deben ser casos fallidos en el proceso de retoque. Las apreciaciones derivadas de esos hallazgos apuntan a productos normalizados, siempre cuadrangulares, de unos 2-3 $\mathrm{cm}$ de lado por 8-9 $\mathrm{mm}$ de espesor, con tendencia piramidal, sección triangular y con retoques de conformación en la mayoría de los lados. Este tipo parece que es el dominante en Espańa (Morgado y
Roncal, 2009: 108) y son similares a los tipos de 0 mechas documentados por Barandiarán (1974: 225) en el taller de Botorrita. Las medidas citadas se aproximan a los valores límite para las piedras de fusil del modelo de 1828 establecidas en 36-32 $\mathrm{mm}^{4}$ para el lado mayor, 30-28 para el lado menor y 8-9 mm de grosor (De Salas, 1833: 346).

La otra vertiente de las actividades de talla parece ir dirigida a la obtención de soportes, lascas sobre las que posteriormente se terminarán de conformar las piedras de chispa en los lugares de uso. La naturaleza masiva del registro arqueológico en las zonas de extracción y talla no permite diferenciar estos productos, pero tal práctica está constatada a nivel documental. De Salas (1833: 345) apunta que la

4 De Salas (1833) da estas dimensiones en 'líneas', según el DRAE, medida longitudinal que equivale a cerca de $2 \mathrm{~mm}$. 
compra de 'lajas finas' en una contrata realizada por la Corona en el Reino de Granada en 1829 se pagaba a 30 reales el millar, más baratas que las piedras de chispa ya elaboradas cuyo coste salía a 40 reales el millar. En la misma línea resulta muy ilustrativa la noticia recogida en el libro del general de brigada $\mathrm{Ma}-$ rio de la Sala (1908) dedicado a los héroes de los sitios de Zaragoza durante la guerra de la Independencia, donde da cuenta de la instalación de un taller de talla en el mesón del Portillo durante el sitio de 1808, con referencias concretas a la talla de sílex procedente de las canteras de Jaulín y La Muela5.

Además, también hay que tener en cuenta el aprovisionamiento de material en bruto sin procesar, como se ha podido documentar en las excavaciones realizadas en el Castillo de los marqueses de Camarasa en $\mathrm{Muel}^{6}$, donde se han localizado abundantes restos líticos en los niveles de la última ocupación -c. 1808- y un posible taller por la concentración de lascas, núcleos, esquirlas y piedras de fusil ya terminadas ${ }^{7}$.
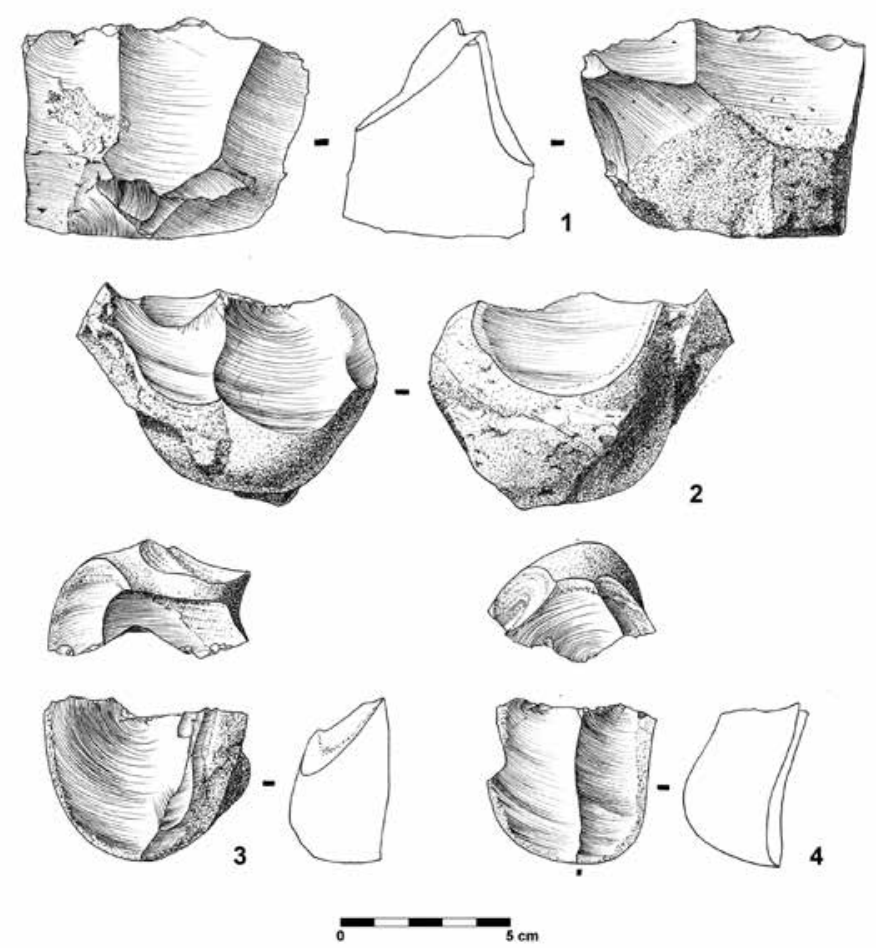

Fig. 15. La Muela: núcleos parciales sobre pequeños nódulos.

5 De la Sala (1908: 94), al tratar la labor del oficial de artillería D. Juan Cónsul, aporta referencias concretas relacionadas con la talla de piedras de chispa entre las actividades esenciales para la defensa de Zaragoza: "Era diaria y apremiante la necesidad de habilitar el armamento, la de proveer al extraordinario consumo de balas de fusil y de cañón, la sustitución de los granos de cobre en las piezas desfogonadas por continuo tronar, la talla de piedras de chispa...". De esta forma el mesón del Portillo se convirtió en una especie de armería con diversos talleres donde, entre otras tareas, se procedía “... á la talla de piedras de chispa, instalando un obrador á cargo del pedrero Antonio Celestino en que se cortaba el excelente pedernal rojo, traído de las canteras de Jaulín, y el negro fino de los montes de La Muela...”.

6 Parece que el castillo se encontraba en estado de ruina en 1755 , siendo ocupado por los ejércitos napoleónicos durante la guerra de la Independencia que procedieron a su voladura parcial cuando lo abandonaron en 1811 (Fatás, L.; Martínez, M. y Reklaityte, I.: Castillo-Palacio de los Marqueses de Camarasa. Informe, expediente: 044/2008, depositado en 2008 en la Dir. Gral. de Patrimonio del Gobierno de Aragón, pp. 2 y 18).

7 Un ejemplo semejante pudo constatarse en las excavaciones del Cuarto Real de Santo Domingo (Granada), publicado por Roncal y Morgado (1995-96), y puede

Ediciones Universidad de Salamanca / 요요

\section{Construcciones asociadas a explotaciones y talleres}

De forma regular se encuentran construcciones rurales asociadas a las explotaciones y/o zonas de talla. Desde el punto de vista etnográfico resulta necesario e interesante documentar estas instalaciones y, desde el punto de vista histórico, es relevante su valoración pues constituye un dato a tener en cuenta para entender los sistemas de explotación que se implementaron.

Hay que aclarar que la asociación construcciones-explotaciones, más allá de compartir los mismos espacios, resulta problemática habida cuenta de que no disponemos de información documental que permita establecer vínculos concretos, pero no es menos cierto que en varios contextos encontramos ambos fenómenos en conexión a partir de una serie de restos arqueológicos, lo que nos puede ayudar a establecer algún tipo de vínculo y explicación.

relacionarse con el abastecimiento del ejército francés ocupante de la Península Ibérica a comienzos del s. XIX.

Zephyrus, LXXXVI, julio-diciembre 2020, 191-216 


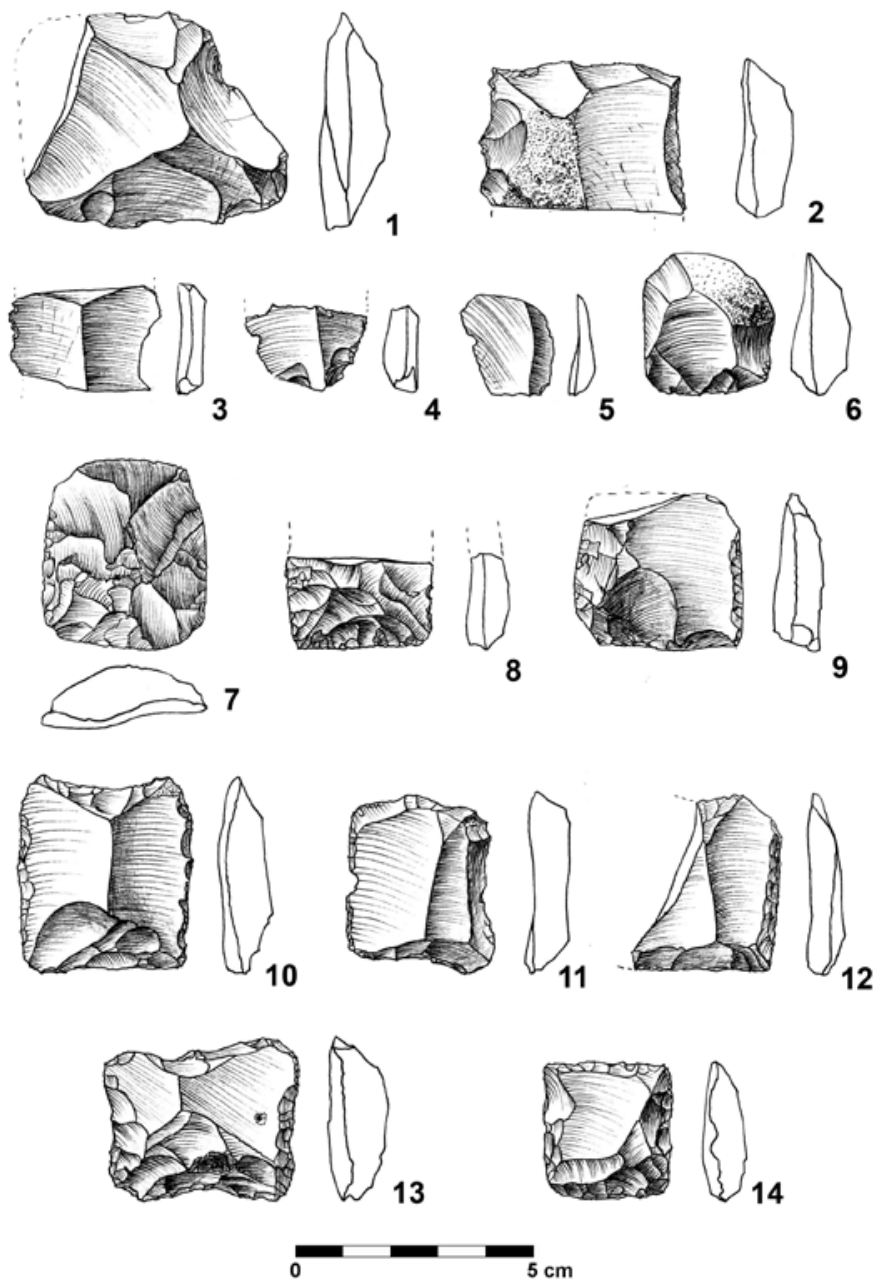

FIG. 16. Piedras de chispa recogidas en la zona del Huerva: 1-2) fragmentos de lascas en fase inicial de transformación; 2-6) lasquitas resultantes de retoque de los soportes; 7-9 y 13-14) piedras de fusilabandonadas en el proceso de configuración final mediante retoque largo/cubriente; 10-12) por fracturación de lascas con retoque corto y semiabrupto.

El catálogo de instalaciones no es muy numeroso y podemos ordenarlo en no más de tres categorías de acuerdo a su entidad: casas-corrales, casetas y cuevas o abrigos acondicionados.

\subsection{Casas-corrales}

La existencia de construcciones rurales con el nombre de 'corrales' o 'parideras' es un rasgo del paisaje

Ediciones Universidad de Salamanca / 요 agrario de estas comarcas. Es normal que se encuentren junto a las explotaciones, sin que ello suponga que, en principio, estén relacionadas. No obstante, hay casos en que la presencia de ciertos elementos arqueológicos o contextuales nos lleva a plantear una posible conexión, como podría apuntarse para varias construcciones del término de Fuendetodos, como el Corral del Blao o las edificaciones arruinadas de Valdezapater I. Ambos lugares se encuentran directamente en los sitios de extracción y procesado.

El Corral del Blao (Fig. 17) está situado en el centro de una serie de pozos y escombreras. Es una construcción robusta, rectangular, que se fue ampliando con sucesivos recintos. Tiene aire de fortificación al contar con pequeñas aspilleras, algunas invertidas, orientadas hacia el $\mathrm{N}$ y o. Más allá de su carácter agrario, parece que estamos ante una construcción defensiva, ya sea relacionada con las explotaciones de sílex o con el control de este paso, también cabañera de ganado, que une el río Huerva y las tierras de Belchite.

Por su parte, Valdezapater I (Fig. 18) es un conjunto de construcciones derruidas en una abrupta ladera que se apoyan en los estratos calcáreos con sílex. Una de las principales galerías excavadas en ellos pudo estar integrada (o reaprovechada) en la parte trasera de la misma edificación, a lo que se une el hecho de que a sus pies, ladera abajo, se extiende una notable escombrera de sílex.

Más allá del carácter 'fortificado y estratégico' del Corral del Blao, ambos lugares pudieron ser sitios de residencia de cuadrillas-familias de pedernaleros dedicados a la explotación de ese recurso inmediato, cuando además se trata de lugares relativamente alejados de los núcleos de población, a 3,6 y 4,7 km de Fuendetodos por caminos tradicionales.

\subsection{Casetas}

Con el nombre de 'casetas' o 'casillas' se conocen construcciones aisladas de una sola estancia 


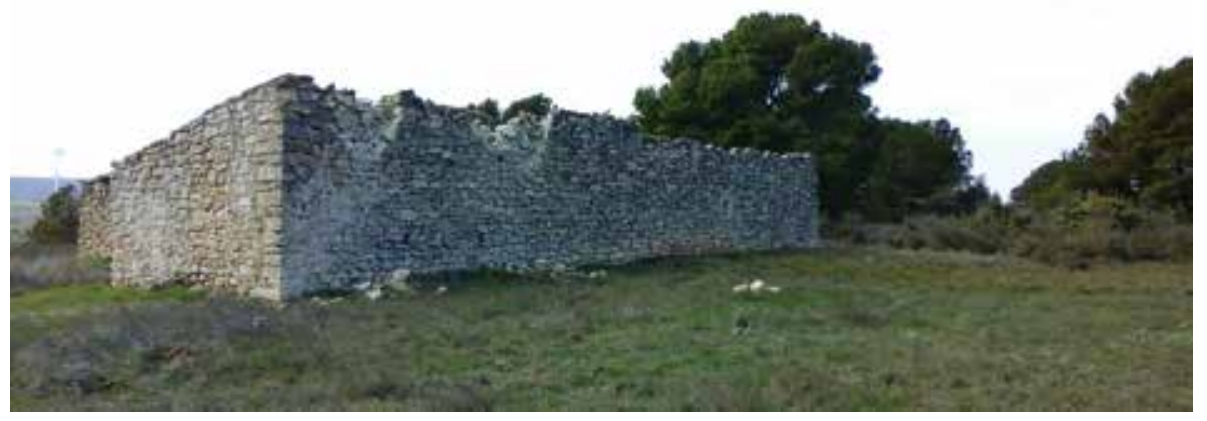

Fig. 17. Corral del Blao (Fuendetodos, Zaragoza): vista del flanco $N$ con aspilleras; a la derecha, entre pinos, los pozos de extracción de silex.

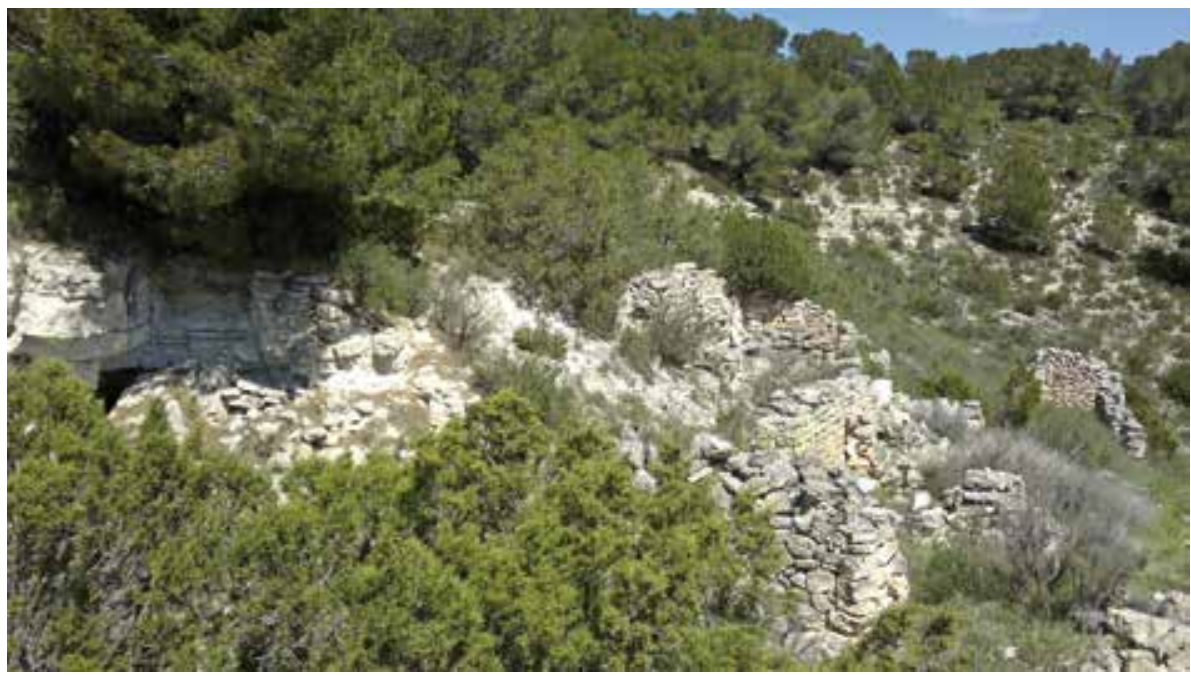

Fig. 18. Valdezapater I (Fuendetodos, Zaragoza): restos de construcciones junto a la entrada a la mina de silex, apenas visible detrás de los restos de las edificaciones. que el interior es un espacio circular de unos $3 \mathrm{~m}$ de diámetro. La cubierta también es de piedra, conformando una falsa cúpula por aproximación de hiladas con relleno interior de tierra con esquirlas de sílex en alguna de ellas. Refuerzos de piedra, a modo de contrafuertes en la parte frontal, a ambos lados de la entrada, alcanzando hasta el dintel de la puerta. Estos contrafuertes curvos dan a la cabaña un aspecto redondeado, aunque su estructura básica exterior sea rectangular (Fig. 19).

En las partidas Opiñén y La Leandra (La Muela), se conservan en estado aceptable un mínimo de 6, distribuidas de forma regular a distancias de 100-250 $\mathrm{m}$ en un polígono de unas 15 ha. Se encuentran siempre junto a las principales explotaciones, pudiendo tratarse de infraestructu- utilizadas como refugio. Son muy frecuentes por toda la comarca como apoyo en las explotaciones agrícolas o ganaderas. El hecho diferencial que nos lleva a relacionarlas con las canteras de sílex es su proximidad y estandarización en forma, tamaño y técnica constructiva, según observamos en el término de La Muela.

Se trata de construcciones robustas, parcialmente excavadas en la parte baja de las laderas. Se levantan mediante gruesos muros de piedra colocada a canto seco, que en la entrada alcanzan $1 \mathrm{~m}$ de espesor. La forma exterior es rectangular, mientras ras vinculadas con ellas, utilizadas por las cuadrillas de pedernaleros trabajando de forma más o menos simultánea en cada uno de los tajos. No obstante, por las dimensiones y la ausencia de cualquier otro tipo de acondicionamiento o resto ${ }^{8}$ no funcionaron como vivienda, sino como refugio temporal. Sí hemos documentado actividad de talla en la puerta de una de ellas.

8 Los restos muebles encontrados junto a las casetas, además del sílex, son algunos fragmentos cerámicos de pequeñas ollas vidriadas para el transporte y consumo de la comida diaria. 

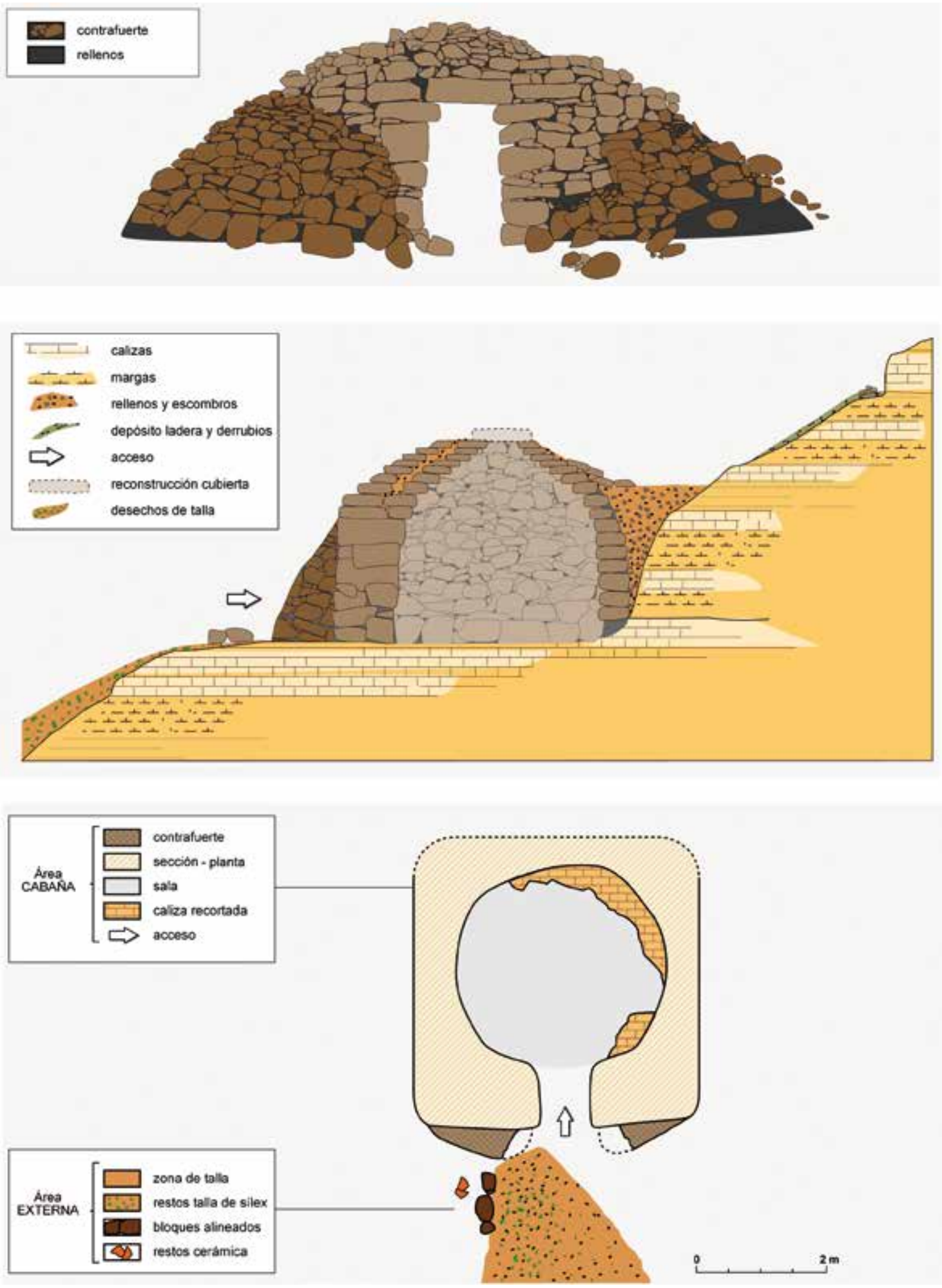

Fig. 19. La Leandra (La Muela), Cabaña 1, representación esquemática. 


\subsection{Covachas y abrigos acondicionados}

También cabe poner en relación con las explotaciones de sílex algunas pequeñas cuevas y abrigos acondicionados (Fig. 20) que han podido ser utilizados como refugio. Se han documentado en las zonas de Jaulín-Botorrita y Fuendetodos. Ya hemos citado varios casos de covachas donde se constatan actividades de talla (Cabezo Negro y Varello de la Calera), que también pudieron ser empleadas como refugio ocasional, aunque es cierto que no hemos encontrado ningún elemento mueble o inmueble que permita suponer esta consideración.

En esas mismas zonas existe algún abrigo acondicionado. Es el caso de Valdezapater II en Fuendetodos (Fig. 20), donde encontramos un pequeño abrigo bajo cornisa, abierto en un banco de calizas tableadas y cerrado mediante una pared de piedra. El muro alcanza el techo del abrigo en toda su longitud, con la entrada orientada al Este y un hueco a modo de ventana en la parte trasera -so-. La técnica constructiva es muy básica, bloques y lajas de piedra caliza colocados en seco y calzados con ripios. De esta forma se genera un pequeño refugio con medidas irregulares que no exceden de 1,4 m de altura, por 1,6 $\mathrm{m}$ de profundidad y unos $3 \mathrm{~m}$ de longitud.

De nuevo hemos de insistir en que no tenemos elementos que nos permitan conectar este tipo de instalaciones con las explotaciones de sílex, más allá de su proximidad y de la lógica de las mismas, por cuanto que las gentes que trabajaron en esa actividad en algún momento pudieron necesitar una protección básica. En cualquier caso, si realmente fueron construidos y utilizados por los pedernaleros, denotan un comportamiento muy distinto al deducido para los conjuntos de La Muela, puesto que responden a una práctica oportunista y ocasional, frente al carácter más estable que proyectan las casetas de piedra, en la línea de lo que apuntan las propias explotaciones.

\section{Los pedernaleros del Huerva a través de la documentación histórica}

El suministro de piedras de chispa para los ejércitos debió estar vinculado a una tradición secular de aprovechamiento local por gentes de la comarca que convivían con estos recursos geológicos. $\mathrm{La}$ aparición del oficio de pedernalero no tuvo por qué diferir de lo ocurrido en otras zonas como el Reino de Granada (Morgado y Roncal, 2009: 139), donde se constatan oficios previos relacionados con la capacidad del sílex para producir chispas como los yesqueros o chisqueros. Su trabajo no implicaba una especial destreza en la talla, por lo que era realizado como complemento de las faenas agrícolas. Sin embargo, los estrictos requerimientos para el engarce de las piedras de chispa en los fusiles con llave de pedernal para la caza o la guerra implicaron formas y tamaños regulares para conseguir una buena adaptación a las pinzas del gatillo. Esta necesidad determinó una talla concreta, lo que unido a la demanda masiva de los ejércitos reales contribuyó a la aparición del oficio especializado de pedernalero que se fue configurando desde principios del s. XvIII y se generalizó a lo largo del mismo.

Los documentos hasta ahora consultados nos relatan que la producción regular de piedras de chispa en el Huerva comenzó a partir de 1760, mediante una petición del Estado a un único productor, Sebastián Mareca de Muel, la talla de cinco millones de piedras de chispa para fusil y medio millón para pistola. Las propias autoridades militares dudaron del cumplimiento del trabajo, ya que, según se relata, un artesano podía fabricar cuatrocientas mil al año. Por ello se hizo acompañar de otros talladores, lo que permitió intensificar la producción y entregar la cantidad acordada en menos de cuatro años. En el año de 1765 se reglamentaron estas entregas, aprobándose la especie de pedernal a trabajar y su forma de trabajo. Además se fijó en un millón de piedras de todos los géneros la producción anual que debían entregar en los almacenes militares de Zaragoza.

No sabemos por qué ese artesano fue reconocido oficialmente frente a otros, pero debemos pensar en su destreza y dedicación exclusiva a la talla del sílex, ya fuera como yesquero o para utensilios agrícolas. Lo cierto es que la vinculación contractual para el suministro regular permitió la especialización y el dominio de una técnica de talla específica necesaria para el buen asiento de las piedras en las armas. 

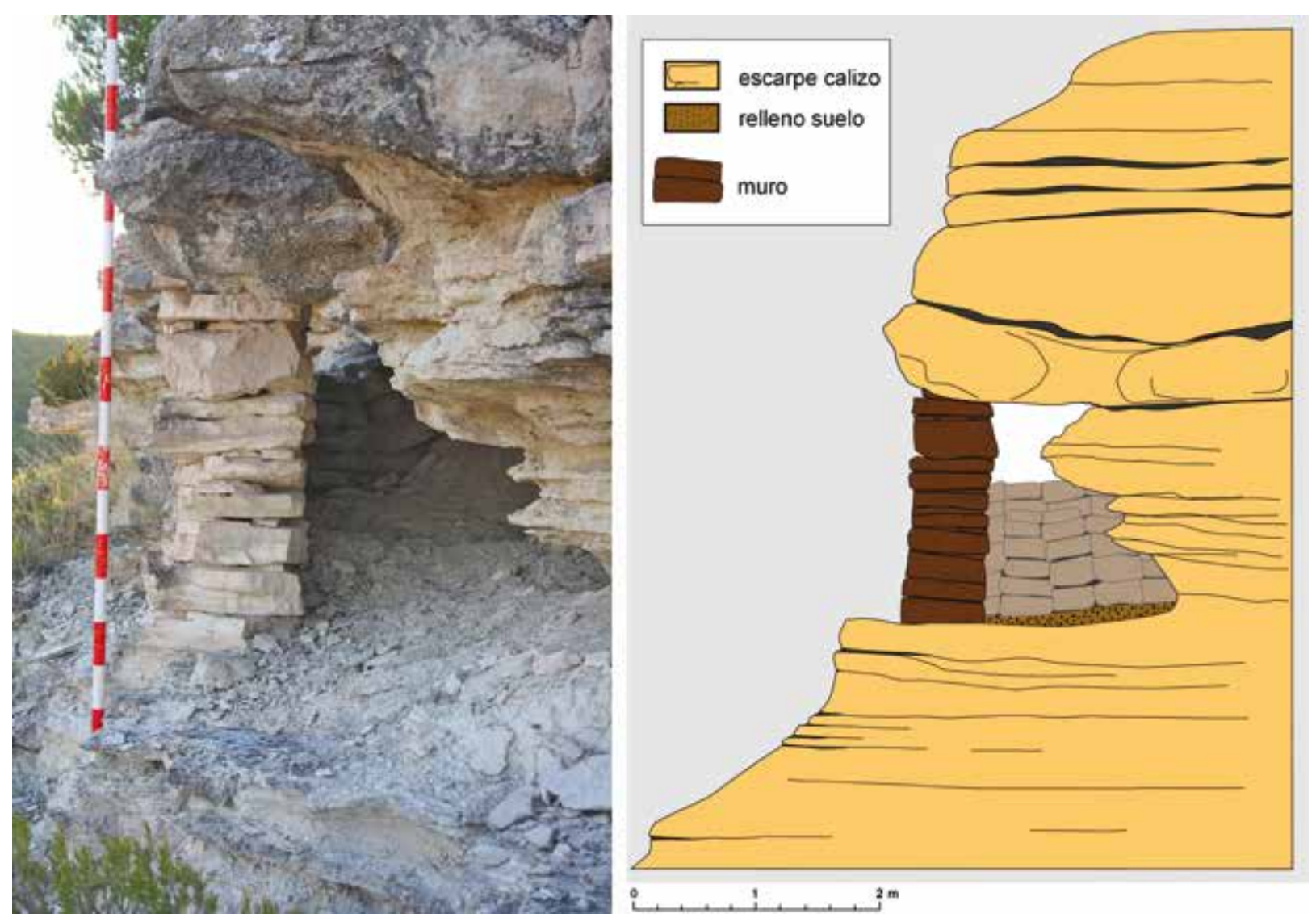

Fig. 20. Valdezapater II (Fuendetodos, Zaragoza): abrigo acondicionado.

En 1776, mediante Real aprobación, se firma la primera contrata para el abastecimiento oficial en exclusiva de piedras de fusil para la Corona, figurando de nuevo Sebastián Mareca a la cabeza de los pedernaleros, el más antiguo de ellos, liberado de otras labores y dedicado en exclusiva a la talla de piedras de chispa?.

En la segunda mitad del s. XviII ya trabajaban para la Corona más de una veintena de artesanos en el valle del Ebro, repartidos entre los pueblos de Botorrita, La Muela, Borja y Muel. Hacia 1777 hay dos grupos trabajando para el Estado residentes en Muel, como se desprende de la documentación de los Archivos de la Corona. El grupo inicial estaba encabezado por Sebastián Mareca con otras nueve personas que poseían la contrata oficial para

9 Archivo General de Simancas (Valladolid), Secretaría de Guerra: serie Artillería, legajo 418. el abastecimiento de este producto. El otro grupo estaba encabezado por Francisco Laora y catorce compañeros. La Corona decidió admitir el mismo número de piedras de fusil a cada grupo y examinar las realizadas por Laora ${ }^{10}$.

Hacia 1779 hay constancia de veinticuatro pedernaleros que trabajaban oficialmente para el Estado. El núcleo central de estos artesanos estaba en el pueblo de Muel, donde se citan diecisiete, mientras que del resto se limitaban a tres de Botorrita y La Muela y uno exclusivamente en Borja, municipio alejado de esta comarca. Por tanto, Muel era el principal centro productor vinculado con la Corona.

Pero además de los artesanos reconocidos oficialmente habría que añadir otros sin relación

10 El examen de las piedras debía ser práctica habitual. De Salas (1833: 346) especifica el precio de ese trabajo a razón de 2,5 reales el millar para producciones granadinas. 
contractual con el cuerpo de Artillería. Así lo refleja la petición de la incorporación de un pedernalero de Muel, Manuel Zapatero, para que se admitiese su producción por aquellas mismas fechas. La petición fue rechazada, ya que el oficio era acaparado de manera gremial por unas cuantas familias, como reflejan los nombres de los artesanos de estos pueblos: familia Rodríguez en Botorrita; Mareca en La Muela $^{11}$, mientras que en Muel destaca la familia apellidada Laora/Lahora, a los que se suman Artigas, Blas, Mainar, Chanzas y Mazas.

El 14 de enero de 1798 se firmó la última contrata documentada con una duración de ocho años. Involucraba a veintiún artesanos, entre ellos ocho de Muel, tres de Botorrita, dos de La Muela, dos de Jaulín y uno del pueblo de María. Se fijaba que cada uno debía elaborar anualmente 75.000 piedras de fusil, 6.667 de pistola y 1.667 de carabina. Es decir, un total de 1.750 .000 piedras de todos los tipos cada año. La producción fue incrementándose a finales del s. XviII con cifras que superaron de largo el millón de piedras solo para el suministro de los ejércitos de la Corona. Además, debemos pensar que una parte de la producción pudo tener otros destinatarios, lo que haría que a lo largo de ese siglo se elaborara una media anual muy superior al millón de piedras de chispa.

Los acontecimientos de la guerra de la Independencia nos aportan algunos datos que resaltan la continuidad del abastecimiento hacia la plaza militar de Zaragoza. Durante el Primer Sitio, en el verano de 1808, algunos lugares se convirtieron en arsenales y talleres de fabricación de todo lo necesario para las armas de fuego, caso del mesón del Portillo (De la Sala, 1908). Entre los operarios que trabajaron en este lugar se encontraba Antonio Celestino, pedrero encargado del obrador en el que se “... cortaba el excelente pedernal rojo, traído de las canteras de Jaulín, y el negro fino de los montes de La Muela..." (De la Sala, 1908: 94). Este artesano estuvo vinculado a la Corona mediante

11 El apellido Mareca aparece vinculado en unos documentos a Muel y en otros a La Muela. Puede ser un error por la similitud entre los dos términos o reflejar cambios en la biografía del individuo y familia. contrata, por lo que sabemos que era oriundo de Jaulín y, junto a su hermano Antonio, ejercían el oficio de pedernaleros. De hecho, según cita de F. Martín Donayre (1873) recogida por Barandiarán (1974: 210) “... en Jaulín y sus contornos es tal la abundancia de pedernal que hasta hace pocos años la construcción en gran escala de piedras de fusil constituía una industria muy importante".

Pasados estos acontecimientos, el trabajo de los artesanos del sílex del río Huerva continuó incluso más allá del silencio que muestra la documentación oficial una vez que las armas de chispa fueron sustituidas a mediados de siglo por los nuevos fusiles de pistón y luego de cartuchos fulminantes. Todavía en 1857, según documentación existente en el Archivo Histórico Municipal de Zaragoza, se autoriza la explotación de una cantera en la localidad de Muel (Tarrińo et al., 2016: 238). En este sentido, no sabemos cuál fue el momento preciso de la extinción de este oficio, pero debió ir paralelo a la desaparición progresiva de las armas de 'llave de chispa', hacia la segunda mitad del s. XIX, solo usadas dentro de un ámbito local.

\section{Discusión y conclusiones}

La producción de piedras de fusil ha sido escasamente tratada en la historiografía española. Hasta finales del s. xx no se acometieron estudios rigurosos basados en análisis arqueológicos y documentales (Barandiarán, 1974; Roncal et al., 1996; Roncal y Morgado, 1995-96, 1998; Morgado y Roncal, 2009) y en la contextualización de esas producciones artesanales en su momento histórico y socioeconómico (Emy, 1978; Forrest, 1983). Desde esta perspectiva, las producciones andaluzas han sido las mejor estudiadas, si bien, de acuerdo con lo que hemos visto, el valle del Ebro, y más concretamente el entorno del río Huerva, deberá aparecer como el otro gran centro productor de piedras de fusil en la Península Ibérica.

La cronología de las explotaciones está bastante bien establecida por diferentes fuentes documentales. A comienzos del s. XviII se impuso el uso de

Zephyrus, LXXXVI, julio-diciembre 2020, 191-216 
armas de fuego con 'llave de pedernal' en el Ejército y en la segunda mitad se producirá el auge de las explotaciones del río Huerva, cuando junto con Granada se convierten en los principales centros de suministro nacionales. El abastecimiento de piedras de fusil se venía practicando a demanda de la Corona según sus necesidades coyunturales, lo que daba lugar en determinados momentos a precios abusivos y la obligación de importar piedras francesas. En la segunda mitad del s. XviII la relación y vínculo entre la Corona y los pedernaleros da un vuelco cuantitativo y cualitativo muy sustancial, imponiéndose un modelo mediante contratas que van a reglamentar todo el proceso productivo y que será clave en el desarrollo de esta actividad en el entorno del río Huerva.

Durante ese tiempo, según la información histórica conocida, la producción de piedras de fusil se convierte en una actividad principal en varios pueblos, aunque es en Muel donde residían el mayor número de artesanos. Así lo constataron los geógrafos de la época al hablar de esta localidad, indicando que las principales actividades industriales fueron la alfarería y las piedras de chispas (Miñano, 1827: 172).

A medida que avanzaba el s. XviII, resultado de esa vinculación contractual con la Corona española, se desarrolló la especialización de estos 'maestros pedernaleros'. El oficio continuó por tradición familiar durante el s. XIX, hasta su definitiva desaparición ante las nuevas necesidades de los ejércitos modernos. En 1833 se siguen citando las canteras de las localidades de La Muela, María, Jaulín, Fuendetodos y Valmadrid como productoras a no “... menos de 10 rs. el ciento...” de piedras de fusil o carabina (Salas, 1833: 345). Pero la producción parece terminar hacia mediados del s. XIX con la incorporación de armas de pistón, aunque, según hemos visto, seguirá cierta actividad extractiva residual seguramente para abastecimiento local o mantenimiento de antiguas armas todavía en uso. De hecho, en el entorno de Pamplona se han encontrado piedras de chispa asociadas a otros restos que pudieron ser utilizadas durante el bloqueo de la ciudad en la 3. a guerra carlista (1874-1875), ya fuera por parte del bando carlista, por voluntarios o por las tropas liberales (Zuazúa, Zuza y García-Barberena, 2016: 313). Por nuestra parte hemos documentado un grafiti con fecha de 1885 y numerosos de la primera mitad del xx en la entrada de alguna de las galerías de las minas de La Muela, lo que no significa que en esas fechas se siguieran explotando más allá de algún aprovechamiento ocasional.

Resulta sorprendente que casi un siglo de explotaciones de sílex en la comarca no haya dejado huella en la memoria de la gente. Actualmente no existe constancia oral de aquella actividad artesanal que debió ser relevante para la economía de algunos individuos, familias y pueblos. La documentación consultada apunta al carácter gremial de los suministros oficiales ligados a algunas familias, pero también hay que prever el trabajo de cuadrillas de pedernaleros relativamente importantes trabajando con cierta intensidad, más allá de los nombres concretos que firman los contratos con la Corona y que aparecen en la todavía escasa documentación conocida, habida cuenta de la importante demanda y del notable impacto en las estribaciones de las plataformas estructurales miocenas en las que se encuentra este recurso.

Si el recuerdo en la memoria de la gente fue efímero, la huella en el paisaje es extraordinaria y constituye uno de los rasgos que caracterizan algunas de las partidas que hemos comentado. La secuencia de cicatrices horizontales, a veces con varias líneas en paralelo, que, con mayor o menor continuidad, recorren las laderas de La Muela, Muel o Jaulín a lo largo de varios kilómetros, se reconoce con relativa facilidad en un entorno de tipo estepario, con escasa vegetación, que, precisamente, tiende a acumularse en los rellanos generados por aquellas zanjas de explotación o de tanteo.

El carácter masivo de las explotaciones y su buena conservación nos revelan un conjunto excepcional, que no tiene nada que envidiar a los grandes centros de producción británicos o franceses. Es por ello que se hace necesario desarrollar un programa de investigación que integre exploraciones arqueológicas con estudios documentales y, desde luego, requiere la adopción de medidas de catalogación, defensa y puesta en valor de un bien destacado y único. 


\section{Fuentes}

Anónimo (1856): Catálogo de los objetos que contiene el Real Museo Militar a cargo del Cuerpo de Artillería. Madrid: Imprenta de Tejado.

De la Sala, M. (1908): Obelisco Histórico en honor de los heroicos defensores de Zaragoza en sus dos sitios (18081809). Zaragoza (reedic. 2008 en formato electrónico IFC). http://ifc.dpz.es/publicaciones/ebooks/id/2835

De Miñano, S. (1827): Diccionario Geográfico-Estadistico de España y Portugal, t. vi. Madrid: Imprenta de Pierart-Peralta.

De Odriozola, J. (1832): Esposicion que hace a la Junta Superior Facultativa del Real Cuerpo de Artillería sobre la fabricación de las piedras de chispa. Madrid: Imprenta E. Aguado.

De Salas, R. (1833): Prontuario de Artillería para el Servicio de Campaña. Madrid: Oficina de E. Aguado.

Martín Donayre, F. (1873): Bosquejo de una descripción física y geológica de la provincia de Zaragoza. Madrid: Memorias de la Comisión del Mapa Geológico de España.

\section{Bibliografía}

Álvarez, A. (1985): "Talleres de sílex de las áreas de los ríos Guadalope y Regallo", Bajo Aragón Prehistoria, v, pp. 87-103.

Ballin, T. B. (2012): "State of the art of British gunflint research, with special focus on the early gunflint workshop at Dun Eistean, Lewis", PostMedieval Archaeology, 46 (1), pp. 116-142. doi: 10.1179/0079423612Z.0000000006

Barandiarán, I. (1974): "Un taller de piedras de fusil en el Ebro Medio", Cuadernos de Etnología y Etnografía de Navarra, 6 (17), pp. 189-228.

Barandiarán, I. y Cava, A. (1985): "Las industrias del Epipaleolítico y del Neolítico en el Bajo Aragón”, Bajo Aragón Prehistoria, v, pp. 49-85.

Bardaviu, V. (1923): "Talleres líticos del hombre prehistórico descubiertos en Alcañiz y en sus contornos", Revista de la Academia de Ciencias Exactas, Físico-Quimicas y Naturales de Zaragoza, vi, pp. 133-165.

Barnes, A. S. (1937): “L'industrie des pierres à fusil par la méthode anglaise et son rapport avec le coup de burin tardenoisien", Bulletin de la Société Préhistorique de France, 34 (7-8), pp. 328-335. doi: 10.3406/bspf.1937.4541 https://www.persee.fr/doc/ bspf_0249-7638_1937_num_34_7_4541

Bea, M.; Domingo, R.; Pérez-Lambán, F.; Reklaityte, I. y URIBE, P. (2010): "Prospecciones arqueológicas en el término municipal de La Muela (Zaragoza)", Salduie, 10, pp. 237-258.

BRANDT, S. (1996): "The ethnoarchaeology of flaked stone tool use in southern Ethiopia”. En Aspects of African archaeology: Proceedings of the Tenth Congress of the Pan African Association for Prehistory and Related Studies. Harare.

Cabello, J. (2005): "El poblamiento prehistórico de las Cinco Villas (Zaragoza). Nuevas vías de aproximación al estudio de los yacimientos líticos de superficie de la Prehistoria Reciente. El Sistema Analítico de Evaluación Habitacional (s.A.E.H.): propuesta metodológica", Salduie, 5, pp. 9-56.

CRUTChley, S. (2015): "Using airborne LIDAR for interpreting archaeological landscapes". En Chavarría, A. y Reynolds, A. (eds.): Detecting and Understanding Historical Landscapes. Mantova: SAP, Società Archeologica, pp. 67-86.

Díez, A. (2005): “Apuntes históricos sobre la colección de minerales, rocas y fósiles de la Academia de Artillería de Segovia", LLUL: Revista de la Sociedad Española de Historia de las Ciencias y de las Técnicas, 28, pp. 383-413.

Dolomieu, C. (1797): "Mémoire sur l'art de tailler les pierres à fusil (silex pyromaque)", Journal des Mines, 6.XXXIII, pp. 693-712.

Domingo, R. (2006): "Les productions de grandes lames dans la région de Montón (Zaragoza, Aragón, Espagne). Étude préliminaire". En VAQUer, J. y Briois, F. (dirs.): La fin de l'Âge de Pierre en Europe du Sud: Matériaux et productions lithiques taillées remarquables dans le Néolithique et le Chalcolithique du sud de l'Europe. Archives d'Écologie Préhistorique. Toulouse, pp. 247-255.

Емy, J. (1978): L'Histoire de la pierre à fusil. Blois: Société d'Exploitation de l'Imprimerie d'Alleaume.

Forrest, A. J. (1983): Master of Flint. Suffolk: Terence Dalton Ltd.

Forrest, C. (2008): "The Nature of Scientific Experimentation in Archaeology: Experimental Archaeology from the Nineteenth to mid Twentieth Century". En Cunningham, P.; Heeb, J. y Paardekooper, R. (eds.): Experiencing Archaeology by Experiment. Oxford: Oxbow Book, pp. 61-68.

García, L. M. y Domingo, R. (2016): "The Monegros-type chert: Petrographic characterization and 
prehistoric use", Journal of Lithic Studies, 3 (2). doi: $10.2218 /$ jls.v3i2.1417

Gould, R. A.; Foster, D. y Sontz, A. (1971): "The lithic assemblage of the Wester Desert Aborigines of Australia”, American Antiquity, 36, pp. 149-169.

Inizan, M.-L.; Reduron, M.; Roche, H. y Tixier, J. (1995): Technologie de la Pierre taillée. Meudon: CREP.

IGTE (1998): Mapa Geológico de España. Escala 1:50.000. Hoja 383 Zaragoza. Madrid: Instituto Tecnológico GeoMinero de España.

Leorza, R. (2013): "Estudio de las materias primas líticas". En Rodanés, J. M. y Picazo, J. V. (eds.): El campamento mesolítico del Cabezo de la Cruz: La Muela, Zaragoza. Monografías Arqueológicas, 45. Zaragoza: Univ. de Zaragoza, pp. 43-73.

Maluquer de Motes, J. (1955): "Los talleres de sílex, al aire libre, del norte de Aragón", Príncipe de Viana, LVIII, pp. 9-32.

Mazo, C. y Cuchi, J. A. (1992): "Sílex y Prehistoria. Análisis mineralógico de muestras silíceas de Huesca y Zaragoza", Bolskan, 9, pp. 9-50.

Morgado, A. y Roncal, E. (2009): Los últimos talladores del sílex. Estudio histórico-arqueológico sobre la explotación del silex en las tierras de Loja y la producción militar de piedras de chispa del reino de Granada durante los siglos XVIII y XIX. Granada: Fundac. Ibn-al Jatib.

Pardo, G.; Arenas, C.; González, A.; Luzón, A.; Muñoz, A.; Pérez, A.; Pérez-Rivarés, F. J.; VÁzQueZ-Urbez, M. y Villena, J. (2004): "Cuenca del Ebro”. En Vera, J. A. (ed.): Geología de España. Madrid: SGE-IGME, pp. 533-543.

Pelegrin, J. (2000): "Les techniques de débitage laminaire au Tardiglaciaire: critères de diagnose et quelques réflexions". En Valentin, B.; Bodu, P. y Christensen, M. (eds.): L'Europe Centrale et Septentrionale au Tardiglaciaire. Mémoire du Musée de Préhistoire d'Ille de France, 7. Nemours: éd. APRAIF, pp. 73-86.

Pérez-Lambán, F.; Fanlo, J. y Picazo, J. V. (2010): "El poblamiento antiguo en el valle del río Huerva. Resultados de las campañas de prospección de 20072009", Salduie, 10, pp. 285-315.

Picazo, J. V. (1986): “Aproximación al conocimiento de los yacimientos líticos del Jiloca-Campo Romanos". En Estudios en Homenaje al Dr. A. Beltrán Martínez. Zaragoza, pp. 285-327.

Picazo, J. V.; Fanlo, J.; Pérez-Lambán, F. y Leorza, R. (2018): "Minas de sílex prehistóricas en el valle medio del Ebro. Las explotaciones de La Leandra (La Muela, Zaragoza)". En Lorenzo, J. I. y Rodanés, J. M. (eds.): Actas II Congreso de Arqueología y Patrimonio Aragonés. Zaragoza: Colegio Oficial de Doctores y Licenciados en Filosofía y Letras y en Ciencias de Aragón, pp. 103-111.

Picazo, J. V.; Pueyo, O.; Sampietro-Vattuone, M. M.; Fanlo, J.; Pocoví, A.; Peña-Monné, J. L.; Tarriño, A. y Pérez-Lambán, F. (2019): "Prospecciones arqueológicas en las explotaciones de sílex de La Leandra (La Muela, Zaragoza)". Póster presentado en el III Congreso de Arqueología y Patrimonio Aragonés (Zaragoza, 2019). doi:10.13140/ RG.2.2.33019.26408

Roncal, M. E.; Martínez, G. y Morgado, A. (1996): "Las piedras de chispa: una producción lítica olvidada en España”, Munibe, 48, pp. 105-123.

Roncal, M. E. y Morgado, A. (1995-96): "El proceso de producción de soportes para piedras de chispa de 'Cuarto Real de Santo Domingo' (Granada)”, Mainake, 17-18, pp. 277-306.

Roncal, M. E. y Morgado, A. (1998): "Sacristía de San Ildefonso (Granada): un ejemplo de estudio histórico-arqueológico de la manufactura de piedras de chispa", Caetaria, 2, pp. 187-198.

Sánchez, M.; García, L. M.; Domingo, R.; Montes, L. y Mangado, X. (2016): "The chert workshop of Tozal de la Mesa (Alins del Monte, Huesca, Spain) and its exploitation in historical times", Journal of Lithic Studies, 3 (2). doi:10.2218/jls.v3i2.1859

Sánchez, M.; García, L. M.; Le Bourdonnec, F. X. y Domingo, R. (2019); "Geochemical fingerprinting of Monegros cherts: Redefining the origin of a prehistoric tracer", Archaeometry, 61 (6), pp. 12331245. https://doi.org/10.1111/arcm.12494

Schleicher, C. (1927): "Une industrie qui disparait: la taille des silex modernes (pierres à fusil et à briquet)", L'Homme Préhistorique, 14 année, n. ${ }^{\circ}$ 5-6, pp. 113-133.

Skertchly, S. B. J. (1879): On the Manufacture of Gunflints: The Methods of Excavating for Flint, the Age of Palaeolithic Man, and the Connexion Between Neolithic Art and the Gun-flint Trade. Memoirs of the Geological Survey of Great Britain: England and Wales. London: H. M. Stationery Office. https:// archive.org/details/cu31924006640837

Stöllner, T. R. (2014): "Methods of Mining Archaeology (Montanarchäologie)”. En Robertsand, B. W. y Thornton, Ch. P. (eds.): Archaeometallurgy in Global Perspective. Methods and Syntheses. New York: Springer, pp. 133-159. 
216 J. V. Picazo Millán, A. Morgado-Rodríguez, J. Fanlo Loras y F. Pérez-Lambán / El aprovechamiento histórico del sílex...

Tarriño, A.; Bea, M.; García, L. M.; Pérez-Lambán, F. y Domingo, R. (2016): "Centros de explotación de sílex en la zona central del Valle del Ebro. La Muela (Zaragoza)", Cuadernos de Prehistoria y Arqueología de la Univ. de Granada, 26, pp. 229-243.

Tindale, N. B. (1965): "Stone implement making among the Nakako, Ngadadjara, and Pitjandjara of the Great Western Desert", Record of the South Australian Museum, 15, pp. 131-164.

Utrilla, M. P. y Tilo, M. A. (1991): "Prospecciones durante 1988 y 1989 en zonas de aprovisionamiento de sílex: bajo Cinca (Fraga, Candasnos) y Pozuelo de Aragón Rueda de Jalón", Arqueología Aragonesa, 1988-1989, pp. 397-405.

VALLESPí, J. E. (1959): “Bases arqueológicas para el estudio de los talleres de sílex del Bajo Aragón”, Cesaraugusta, 13-14, pp. 8-20.

White, S. W. (1963): "On the origins of gunspalls", Historical Archaeology, 9, pp. 65-73.

Zuazúa, N.; ZuZa, C. y García-Barberena, M. (2016):

"Evidencias arqueológicas del bloqueo de Pamplona (1873-1874)”, Trabajos de Arqueología Navarra, 28, pp. 309-317. 